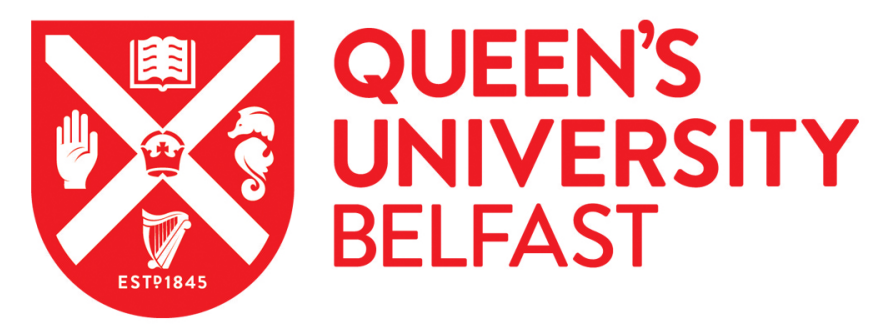

\title{
Probing the activities of UV and visible-light absorbing photocatalyst powders using a resazurin-based photocatalyst activity indicator ink (Rz Paii)
}

Mills, A., Wells, N., \& O'Rourke, C. (2017). Probing the activities of UV and visible-light absorbing photocatalyst powders using a resazurin-based photocatalyst activity indicator ink (Rz Paii). Journal of Photochemistry and Photobiology A: Chemistry, 338, 123-133. https://doi.org/10.1016/j.jphotochem.2017.01.030

Published in:

Journal of Photochemistry and Photobiology A: Chemistry

\section{Document Version:}

Peer reviewed version

Queen's University Belfast - Research Portal:

Link to publication record in Queen's University Belfast Research Portal

\author{
Publisher rights \\ (C) 2017 Elsevier B. V. This manuscript version is made available under the CC-BY-NC-ND 4.0 license \\ http://creativecommons.org/licenses/by-nc-nd/4.0/,which permits distribution and reproduction for non-commercial purposes, provided the \\ author and source are cited.
}

\section{General rights}

Copyright for the publications made accessible via the Queen's University Belfast Research Portal is retained by the author(s) and / or other copyright owners and it is a condition of accessing these publications that users recognise and abide by the legal requirements associated with these rights.

Take down policy

The Research Portal is Queen's institutional repository that provides access to Queen's research output. Every effort has been made to ensure that content in the Research Portal does not infringe any person's rights, or applicable UK laws. If you discover content in the Research Portal that you believe breaches copyright or violates any law, please contact openaccess@qub.ac.uk. 


\title{
Probing the activities of UV and visible-light absorbing photocatalyst powders using a resazurin-based photocatalyst activity indicator ink (Rz Paii)
}

\author{
Andrew Mills*, Nathan Wells, Christopher O’Rourke \\ Queen's University of Belfast, School of Chemistry and Chemical Engineering, Stranmillis Road, \\ Belfast, BT95AG \\ e-mail: andrew.mills@qub.ac.uk
}

\begin{abstract}
A variety of semiconductor photocatalyst powdered materials, i.e. $\mathrm{TiO}_{2}, \mathrm{CdS}, \mathrm{WO}_{3}$ and $\mathrm{C}_{3} \mathrm{~N}_{4}$, are able to mediate the UV (365 nm) photocatalysed reduction of Rz (blue) to Rf (pink) by glycerol, when used as a dispersion in deaerated, aqueous solution. Under the same conditions, but using visible $(455 \mathrm{~nm})$ light, the same reaction is promoted by the visible-light absorbing semiconductors, $\mathrm{CdS}, \mathrm{WO}_{3}$ and $\mathrm{C}_{3} \mathrm{~N}_{4}$. These powders are mixed with $\mathrm{SiO}_{2}$ and PTFE powder and pressed as discs, for assessment using a Rz Photocatalyst Activity Indicator Ink, i.e. Rz paii, coated onto the surface of each disc. Results show that only the $\mathrm{TiO}_{2}$ pressed film, with UV irradiation, is able to photocatalyse the reduction of $\mathrm{Rz}$ to $\mathrm{Rf}$, under ambient conditions, due to competition from ambient air. However, when covered with Sellotape ${ }^{\mathrm{TM}}$ to exclude $\mathrm{O}_{2}$, all but the $\mathrm{C}_{3} \mathrm{~N}_{4}$ photocatalyst demonstrated photocatalytic activity, and in the same order as observed in solution for this reduction reaction, using UV or visible light. Irradiations carried out using $617 \mathrm{~nm}$ light on the same systems reveal that the dye is slowly bleached, at a rate that this largely independent of the semiconductor/insulator present, and no $\mathrm{Rf}$ is generated, suggesting dye degradation via photolysis rather than dye sensitisation. This is the first example of the use of an Rz paii responding to visible light absorbing photocatalysts and the first example of an Rz paii being used to assess the photocatalytic activity of powdered SC photocatalysts.
\end{abstract}

Key words: resazurin; reduction; inks; powder; UV; visible 


\section{Introduction}

Semiconductor photocatalysis is a well-established research subject which has led to a number of significant commercial products, such as: 'self-cleaning' glass, tiles, concrete, paint and fabrics [1,2]. In almost all such commercial products the active ingredient is a semiconductor, SC, where $\mathrm{SC}=\mathrm{TiO}_{2}$, which absorbs ambient light (UV light if $\mathrm{TiO}_{2}$ is used), from a solar or artificial light source, to produce electron-hole pairs, which can recombine, in the bulk or at the surface of the semiconductor or, most importantly for semiconductor photocatalysis, react with surface-adsorbed species [3]. Most commercial photocatalytic commercial materials use the $\mathrm{SC}$, usually $\mathrm{TiO}_{2}$, to mediate the photo-oxidation of adsorbed organic species, either dissolved in solution, or in the form of volatile organic carbons, to their mineral form, with the concomitant reduction of adsorbed $\mathrm{O}_{2}$ to water, i.e.

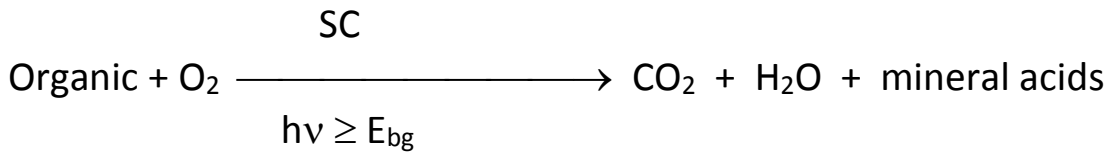

where, hv is the energy of the incident light which must be greater than or equal to the bandgap energy of the SC, $E_{b g}$, and where too, mineral acids are generated if the organic species has one or more heteroatoms, such as $\mathrm{S}, \mathrm{Cl}$ or $\mathrm{N}$, in its structure [1]. Another important application is the use of some $\mathrm{SC}^{\prime} s, \mathrm{TiO}_{2}$ in particular, to mediate the photooxidation of $\mathrm{NO}_{x}$, i.e. $\mathrm{NO}$ and $\mathrm{NO}_{2}$, to nitrate [4].

In research and industry it is obviously essential to assess and compare the activities of new and existing photocatalytic materials. It is not surprising, therefore, to note that in recent years a number of different tests for this purpose have been developed into ISO standards [5]. These tests include: the photo-oxidative bleaching of methylene blue, $\mathrm{MB}$, in aqueous solution, i.e. reaction (1), with organic $=\mathrm{MB},[6]$ and the photo-oxidation of $\mathrm{NO}_{\mathrm{x}}$ gases [7]

At present there is no ISO for testing photocatalytic powders, despite the fact that many of the new photocatalytic materials that are reported in the literature are in powder form. In research, however, the most popular approach to assessing the photocatalytic activity of powdered SCs is to disperse the semiconductor photocatalyst powder under test in an aqueous solution of a dye, such as $\mathrm{MB}$ or Acid Orange 7, $\mathrm{AO7}$, and monitor the rate of photobleaching of 
the dye, which is presumed to be via the oxidation reaction (1) [8]. This method of testing is appropriate when the excitation light, i.e. hv, is NOT absorbed, or absorbed very weakly, by the dye itself. Thus, the MB ISO [6], for photocatalytic films specifies that it is for UVA (NOT visible) excitation only, since $\mathrm{MB}$ absorbs very little UVA light emitted by the black light (BL) or blacklight blue (BLB) lamps required by this ISO.

If the excitation light does comprise a significant level of photons of wavelengths which will be strongly absorbed by the dye, then a non-photocatalytic, dye-bleaching processes, such as dye photolysis $[9,10]$, or dye-photosensitisation $[8,11,12]$, can be very effective in bleaching the dye.

The dye photosensitisation process usually involves the electronic excitation of the dye, $D$, to $D^{*}$, by light of sufficient energy, $h v^{\prime}$, which allows it to inject an electron into the conduction band of the semiconductor, SC, which in turn then reacts with an oxidizing agent, Ox, present in the system $[8,11]$. The process can be summarized as follows:

$$
\begin{array}{cc}
\mathrm{h} v^{\prime} & \mathrm{Ox} \\
\mathrm{D} \longrightarrow \mathrm{D}^{*} \longrightarrow \mathrm{D}^{+\bullet}+\mathrm{SC}\left(\mathrm{e}^{-}\right) \longrightarrow \mathrm{D}^{+\bullet}+\mathrm{Ox}^{-}
\end{array}
$$

where $\mathrm{D}^{+\bullet}$ is an oxidized radical of the dye that is unstable and able to react further to produce colourless degradation products. Usually, $\mathrm{Ox}$ is $\mathrm{O}_{2}$, although other oxidizing agents, such as $\mathrm{H}_{2} \mathrm{O}_{2}, \mathrm{Fe}^{3+}$ and $\mathrm{Cu}^{2+}$, have been used for the same purpose. A classic example is provided the work of Wu et al., in their study of the photosensitized bleaching of Rhodamine B under visible light in aqueous dispersion of $\mathrm{TiO}_{2}$ [12], and the reviews of Rochin et al. [11] and Rajeshwar et al. [8] provide many more such examples. Note, however, that in most, if not all reported cases, an oxidizing agent, usually $\mathrm{O}_{2}$, is present and, in contrast, most of the work described here is carried out under anaerobic conditions, in the presence of a notable sacrificial electron donor, glycerol, rendering a dye-photosensitisation reaction unlikely.

If dye photolysis or dye photosenstisation occurs, then a photocatalyst can appear to exhibit visible light photocatalytic activity, whereas in fact the observed photobleaching of the dye is NOT associated with semiconductor photocatalysis, i.e. reaction (1), but instead is due to a dye photolysis and/or dye photosensitisation processes (reaction (2). 
An excellent example of the above has been reported by Ohtani and his co-workers [13], in a study of the $\mathrm{MB} / \mathrm{TiO}_{2} / \mathrm{O}_{2}$ system which showed that the action spectrum (wavelength dependence of photoinduced reaction rate) resembled that of the diffuse-reflectance spectrum of surface-adsorbed $\mathrm{MB}$, as would be expected for a dye-sensitised reaction. Interestingly, using the same system and technique, these workers also reported that a sulfur-doped $\mathrm{TiO}_{2}$ catalyst 'has activity under visible light and that the decomposition mechanism depends upon excitation wavelength', implying that using a dye to assess photocatalytic activity is possible, provided a suitable wavelength of excitation is used, as in the case of the $\mathrm{S}-\mathrm{TiO}_{2}$. Clearly it is vital to identify and utilize a wavelength region(s), $\mathbf{W R}(\mathbf{S C})$, where the semiconductor absorbs and the dye does not, before any claim of photocatalysis (especially visible light photocatalysis) can be made. These workers also suggest rightly here [13] and later [14] that the usual control experiments, i.e., negligible photoinduced $\mathrm{MB}$ degradation in the absence of $\mathrm{TiO}_{2}$, cannot exclude the participation of dye-sensitization and so is flawed.

Although Ohtani et al. suggest that in such a system an action spectrum is needed in order to identify the 'origin of the photoresponse' [13], this is often unnecessary, especially if the object is to identify a $\mathbf{W R}(\mathbf{S C})$. Instead, it is more usual, quicker and convenient to run the UV/Vis absorption or diffuse reflectance (DRS) spectroscopy of the system, and the individual components, so as to reveal where the SC and dye absorb, and, more crucially, if there is a suitable $\mathbf{W R ( S C )}$ from which to select an excitation wavelength. In addition, such work will reveal if a charge transfer, CT, complex is formed between the $\mathrm{SC}$ and the substrate, which are well-known for $\mathrm{TiO}_{2}$, for example, when using simple molecules, such as: catecholate-type ligands [15], phenols [16,17] and aromatic carboxylic acids [17], as the 'test pollutant'. These CT complexes are usually identified via the appearance of additional absorption bands, often in the visible, in the DRS.

In a SC/dye system where a $\mathbf{W R ( S C )}$ can be identified, by UV/Vis absorption or DR spectroscopy, it is reasonable to use it to select an excitation wavelength to assess the activity of the SC, i.e. without recourse to recording an action spectrum. A classic example of this is $M B$, which, from its absorption spectrum, absorbs little in the UVA region, especially around $365 \mathrm{~nm}$, and as a consequence has been used routinely over the years in the assessment of the activity of many UV-absorbing semiconductors [8] and is the basis of one of the most established ISO tests $[6,18]$. In contrast, as noted above, Ohtani et al found $\mathrm{MB}$ unsuitable for assessing the photocatalytic activity of visible light photocatalysts, at high 
concentrations at least $\left(5 \times 10^{-5} \mathrm{M}\right)$, because its absorption spectrum is appreciable throughout the visible region, 400-680 nm; i.e. $\lambda_{\max }=665 \mathrm{~nm}$, Half (PeaK) BandWidth $(H B W)=$ ca. $150 \mathrm{~nm}[13]$.

The above concern has not stopped many from using $M B$, and other dyes, to test the photocatalytic activity of visible-absorbing semiconductors via reaction (1), however, nowadays, the more wary researcher tends to shy away from using it, and other dyes, such as A07, due to the often potentially ambiguous nature of the results. In summary, although dyes can be used as a method for testing photocatalyst activity, great care needs to be taken to ensure that the incident excitation light is NOT absorbed, or absorbed very weakly, by the dye itself [19].

In recent years, this group has developed a rapid, simple method for assessing the activities of photocatalytic films, involving the use of photocatalyst activity indicator inks (paiis) [20-22]. The most used and effective of the paiis developed so far employs the redox dye, Resazurin $(R z)$, which is blue and readily, and irreversibly, reduced by the photogenerated electrons on $\mathrm{TiO}_{2}$ for example, to resorufin (Rf), which is pink [20,21]. This reduction reaction is accompanied by the concomitant rapid and irreversible reaction of the photogenerated holes with glycerol, which is also present in the ink film. The overall photocatalytic process is as follows:

$$
\text { Glycerol }+R z \underset{h v \geq E_{b g}}{\longrightarrow} \text { glyceraldehyde + Rf }
$$

where, in the case above, $\mathrm{SC}=\mathrm{TiO}_{2}$ and $\mathrm{hv}=\mathrm{UV}$. Other work has established the existence of a direct correlation in the rate of photocatalysed reduction of $\mathrm{Rz}$ in an Rz paii, via reaction (3) with that of the photocatalysed oxidation of a thin solid organic film (stearic acid) or MB in solution, via reaction (1), when mediated by a $\mathrm{TiO}_{2}$ film, and electronically excited using UVA radiation $[21,23]$. Typically, the Rz paii test is completed within a few minutes, and so much faster than any of the more traditional tests based on reaction (1). For example, the Rz paii test is typically 45 times faster than the MB in solution ISO test, when using commercial selfcleaning glass. 
To date, the Rz paii test has been developed and used for testing films of UV-absorbing photocatalysts, such as $\mathrm{TiO}_{2}$; it has never before been used to test the activities of SC powders, especially not visible light absorbing powders. However, as described above, under certain conditions this is possible and enables us to study the use of an Rz paii as a probe of the activities of pressed powder discs of a number of established UV and Visible light-absorbing SC's, using either UVA radiation (365 nm), or visible light (455 $\mathrm{nm}$ ) as the excitation radiation. Specifically, in this work high energy LEDs, with peaks at 365 and $455 \mathrm{~nm}$, are used to provide, the necessary narrow bands (average HBW =13 nm) of excitation light, the peak wavelengths of which were chosen, based on UV/Visible absorption and diffuse reflectance, spectroscopy, so that the incident excitation light is NOT absorbed, or very weakly so, by the Rz dye itself.

\section{Experimental}

\subsection{Materials:}

P25 titania was supplied by Degussa (Evonik). Unless otherwise stated, all other materials were purchased from Sigma Aldrich and used as received. All UV-vis spectra were recorded using an Agilent Technologies Cary $50 \mathrm{UV} /$ vis spectrophotometer. The $\mathrm{C}_{3} \mathrm{~N}_{4}$ photocatalyst powder was prepared using a literature method [24], in which, briefly, $10 \mathrm{~g}$ of urea were placed in a crucible and heated to $550^{\circ} \mathrm{C}$ at a ramp rate of $15^{\circ} \mathrm{C} \mathrm{min}-1$ and held there for $2 \mathrm{~h}$, before being allowed to cool in air. Once cooled to room temperature, the pale yellow powder was used without further treatment. The XRD pattern recorded for the powder corresponded to that reported for $\mathrm{C}_{3} \mathrm{~N}_{4}[25]$.

\subsection{Characterisation of the semiconductor photocatalysts}

The specific surface area of each of the different semiconductor powders used in this work was determined using the BET $\mathrm{N}_{2}$ adsorption method (Micromeritics Tristar 3020 instrument). The X-ray diffraction patterns, used to identify the crystal phase of each of the semiconductor 
photocatalyst powders, were determined using a Panalytical X'pert powder X-ray diffractometer with $\mathrm{Cu} \mathrm{K \alpha}$ radiation $(\lambda=1.5406 \mathrm{~nm})$ at $40 \mathrm{kV}$ and $40 \mathrm{~mA}$ with a step size of $0.06^{\circ}$. Bandgap $\left(E_{b g}\right)[26]$, band position (i.e. of the conduction and valence band, $E_{C B}$ and $E_{V B}$ ) [26] and point of zero charge values [26-31] were gleaned from the literature. Table 1 lists these key characteristics of the tested semiconductor powders.

Table 1: Semiconductor photocatalysts characteristics

\begin{tabular}{|c|c|c|c|c|c|c|c|}
\hline Powder & Colour & $\mathrm{E}_{\mathrm{cb}} / \mathrm{V}^{\mathrm{a}}$ & $E_{v b} / V^{a}$ & $E_{b g} / e V$ & $\begin{array}{l}\text { Surface Area } \\
/ \mathrm{m}^{2} \mathrm{~g}^{-1}\end{array}$ & $\begin{array}{l}\text { Crystalline } \\
\text { Form }\end{array}$ & p.z.c \\
\hline $\begin{array}{l}\mathrm{SiO}_{2} \\
\text { (Aldrich, S5631) }\end{array}$ & White & -- & -- & ca. 9.3 & 6.9 & quartz & 3.7 \\
\hline $\mathrm{P} 25\left(\mathrm{TiO}_{2}\right)$ & White & -0.29 & 2.91 & 3.2 & 53 & $\begin{array}{l}\text { anatase, } \\
\text { rutile }\end{array}$ & 6.2 \\
\hline $\mathrm{C}_{3} \mathrm{~N}_{4}$ & Yellow & -0.83 & 1.87 & 2.7 & 111 & graphite like & 7.2 \\
\hline $\begin{array}{l}\mathrm{WO}_{3} \text { (nano) } \\
\text { (Aldrich, } \\
550086)\end{array}$ & Green & 0.17 & 2.87 & 2.7 & 23 & monoclinic & 1.5 \\
\hline $\begin{array}{l}\text { CdS } \\
\text { (Aldrich, } \\
217921 \text { ) }\end{array}$ & Orange & -0.52 & 1.88 & 2.4 & 54 & hexagonal & 2 \\
\hline
\end{tabular}

a: Band positions quoted with respect to the NHE at $\mathrm{pH} 0$. 


\subsection{Irradiation sources}

All irradiations were carried out using one of three different high power light emitting diodes, LEDs, purchased from RS Components. The three LEDs had emission peaks (see figure 1) at the following wavelengths; 365 nm (HBW = 10 nm; LED Engin, LZ1 UV LED 365 nm Gen 2 (Maximum wattage $=2.8 \mathrm{~W}$ ), $455 \mathrm{~nm}(\mathrm{HBW}=16 \mathrm{~nm}$; OSLON+ PowerStar Deep Blue 455nm (Maximum wattage > $2.2 \mathrm{~W}$ ), and ThorLabs; $617 \mathrm{~nm}$ (HBW = $14 \mathrm{~nm}$; Thorlabs High-Power LED M617D2 (Maximum wattage $=2.2 \mathrm{~W}$ ).

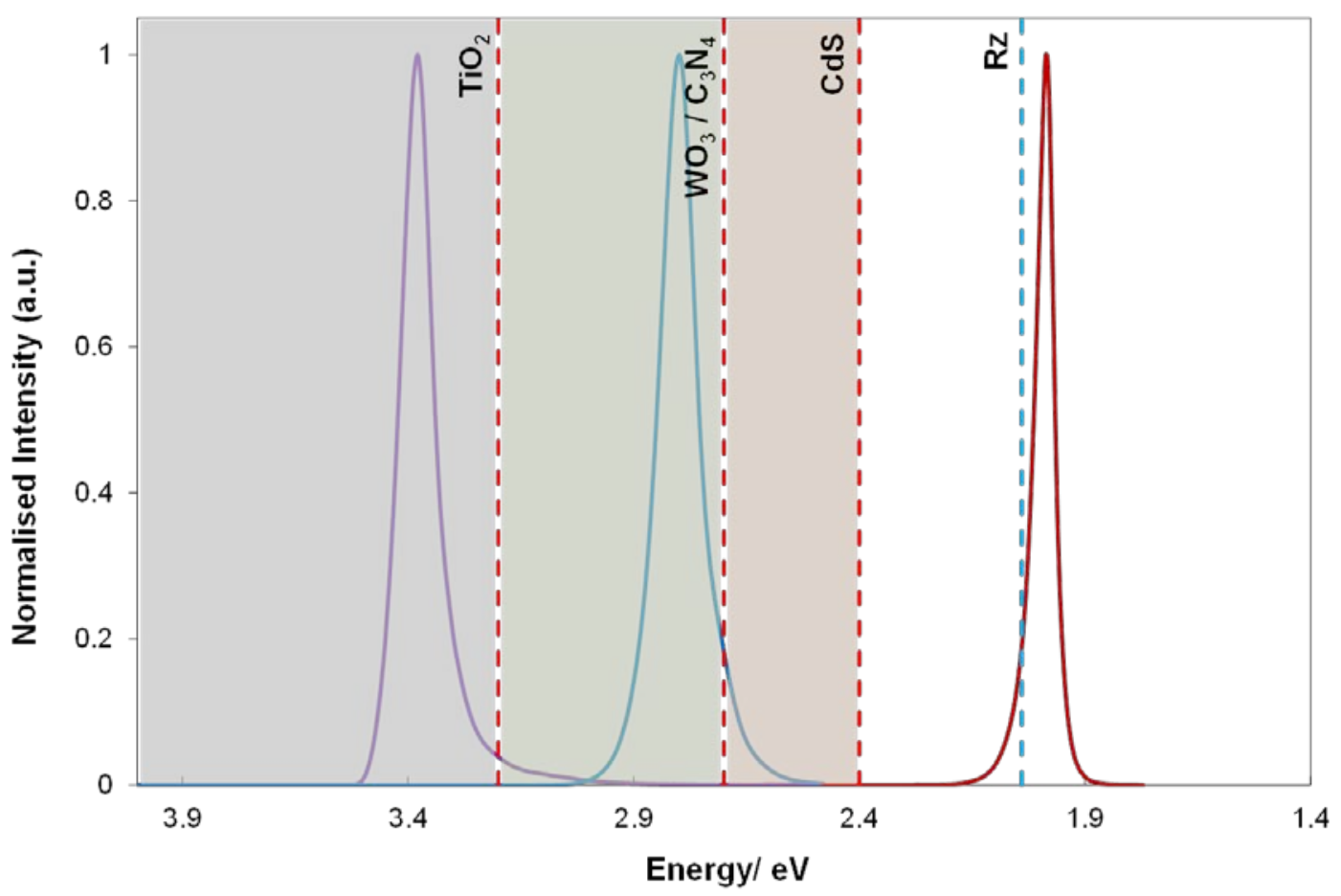

Figure 1: Emission spectra of the 365, 455 and $617 \mathrm{~nm}$ LEDs (HBW's $=10,16$ and $14 \mathrm{~nm}$, respectively) and bandgap energies (broken red lines) of the different semiconductors used in this work. The broken blue line is the energy associated with the $\lambda(\max )$ value for $R z$ in aqueous solution. The intensity of each LED has been normalised to the peak LED emission output, measured with respect to power (i.e. $\mu \mathrm{W} \mathrm{cm} \mathrm{cl}^{-1} \mathrm{eV}^{-1}$ )

The emission spectra (irradiance: in units: $\mu \mathrm{W} \mathrm{cm} \mathrm{eV}^{-1}$ (or $\mathrm{nm}^{-1}$ ) versus wavelength) of the LEDs used in this work were recorded using a spectroradiometer (model: OL756, Gooch \& Housego) and are illustrated in figure 1, along with the bandgap energies of the different 
semiconductors used and the $\lambda(\max )$ value for $R z$ in aqueous solution. The same spectroradiometer was used to determine the typical irradiance value exhibited by each LED, when used to irradiate the different samples (solutions and films). Thus, the irradiance values used for the films were: 1.5, 14 and $10 \mathrm{~mW} \mathrm{~cm}^{-2}$ for the 365, 455 and $617 \mathrm{~nm}$ LEDs, respectively, at a distance of $3 \mathrm{~cm}$ from the film sample (beam size $=\mathrm{ca} .6 .5 \mathrm{~cm}$ ). For the solution work, the LED was held $2 \mathrm{~cm}$ from the side of the cuvette giving a beam size of ca. $5 \mathrm{~cm}$ and irradiances of 5, 20, and $15 \mathrm{~mW} \mathrm{~cm}^{-2}$ for the 365,455 , and $617 \mathrm{~nm}$ LEDs respectively.

\subsection{Solution irradiations}

Solutions were prepared by adding the photocatalyst powder under test (usually $5 \mathrm{mg}$, but for $\mathrm{WO}_{3}$ and $\mathrm{C}_{3} \mathrm{~N}_{4}, 10$ and $50 \mathrm{mg}$, respectively) to an aqueous solution of glycerol, in order to generate dispersions that absorbed sufficient incident light so as to effect measurable rates of dye photo-bleaching. The latter translated to a typical background absorbance for each dispersion at $800 \mathrm{~nm}$ of ca. 0.18 ; and the higher concentrations of $\mathrm{WO}_{3}$ and $\mathrm{C}_{3} \mathrm{~N}_{4}$ were required because they didn't form very good, stable dispersions, in comparison to the other semiconductors. Note also that for $\mathrm{WO}_{3}$ only, the $\mathrm{pH}$ of the dispersions, before dye addition was ca. 4.1, and given the $\mathrm{pK}_{\mathrm{a}}$ of $\mathrm{Rz}$ is 5.7 , the dispersions had to be $\mathrm{pH}$-adjusted to 7.5.

The solution to which each semiconductor powder was added comprised $100 \mathrm{~g}$ of 10 wt.\% aqueous solution of glycerol. The resulting dispersion was then agitated to ensure a uniform suspension of the catalyst. For each irradiation, the suspension under test was purged with argon under constant stirring for 10 minutes, after which $3 \mathrm{~mL}$ of the suspension were transferred to an argon purged, $1 \mathrm{~cm}$ cuvette equipped with a crown-shaped stirrer (VWR, product no: 442-0502). To this dispersion, a $30 \mu \mathrm{L}$ plug of $2 \times 10^{-2} \mathrm{M} \mathrm{Rz}$ was injected to give an initial dye concentration of $2 \times 10^{-5} \mathrm{M}$. The cuvette was then sealed to prevent air leaking into the reaction cell, and placed inside a UV-vis spectrophotometer, where it was irradiated in-situ, using one of the specified LEDs, see section 2.3, under constant stirring and the change in absorbance spectrum of the dye solution monitored spectrophotometrically as a function of irradiation time, $t$. 


\subsection{Preparing pressed film photocatalyst}

A range of semiconductor powders were pressed into $13 \mathrm{~mm}$ diameter (1 $\mathrm{mm}$ thick) discs using an IR pellet press die (Specac). When the neat semiconductor powders, with 15 wt\% PTFE powder binder (Aldrich Chemicals) were used to make the discs, see figure 2, they proved - for the most part - to be much too photoactive to enable their ready assessment using the Rz ink. Thus, instead, the discs were made using usually $\mathrm{SiO}_{2}$ - a non-photocatalytic, insulator oxide mixed with the PTFE powder binder in a 50:50 ratio, and $1 \mathrm{wt} \%$ of the semiconductor under test. In such cases, $20 \mathrm{mg}$ of the semiconductor (P25, $\left.\mathrm{WO}_{3}, \mathrm{CdS}\right)$ were added to $1.98 \mathrm{~g}$ of the 50:50 $\mathrm{SiO}_{2}$ /PTFE mixture and ground together in a mortar and pestle to produce a well dispersed 1\% SC loaded powder, $200 \mathrm{mg}$ of which were then transferred into a $13 \mathrm{~mm} \mathrm{KBr}$ die and subjected to $2 \mathrm{~T}$ of pressure for ca. $5 \mathrm{~s}$. Photographs and diffuse reflectance spectra, of the original powders, the neat discs (15 wt\% PTFE) and the more $\mathrm{SiO}_{2}$ diluted discs are illustrated in figure 2 . 


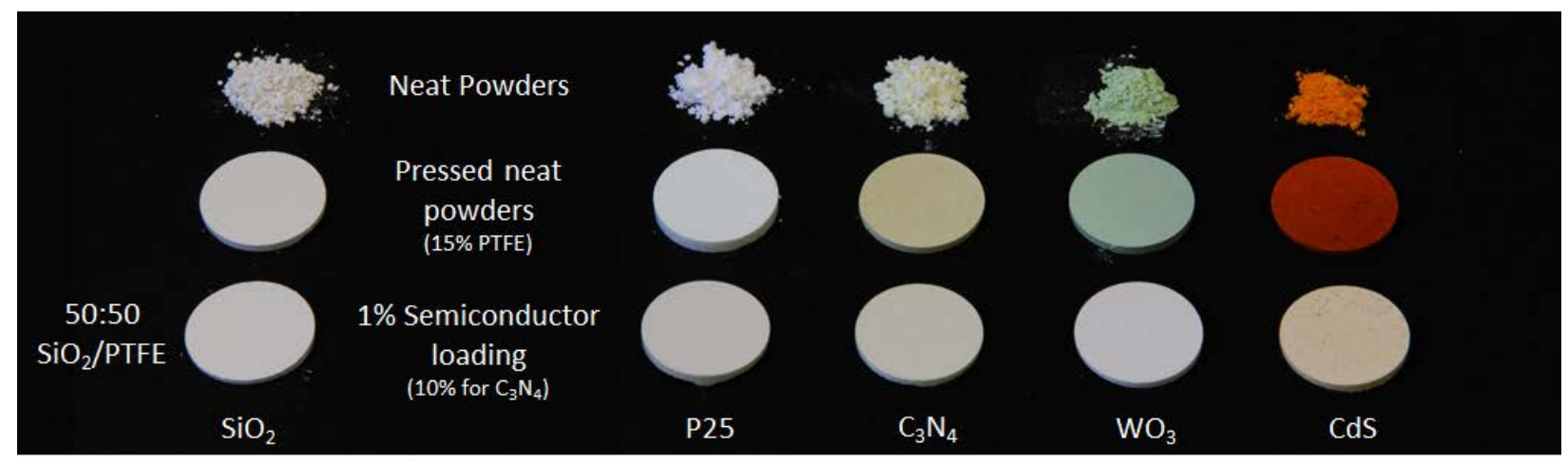

(a)

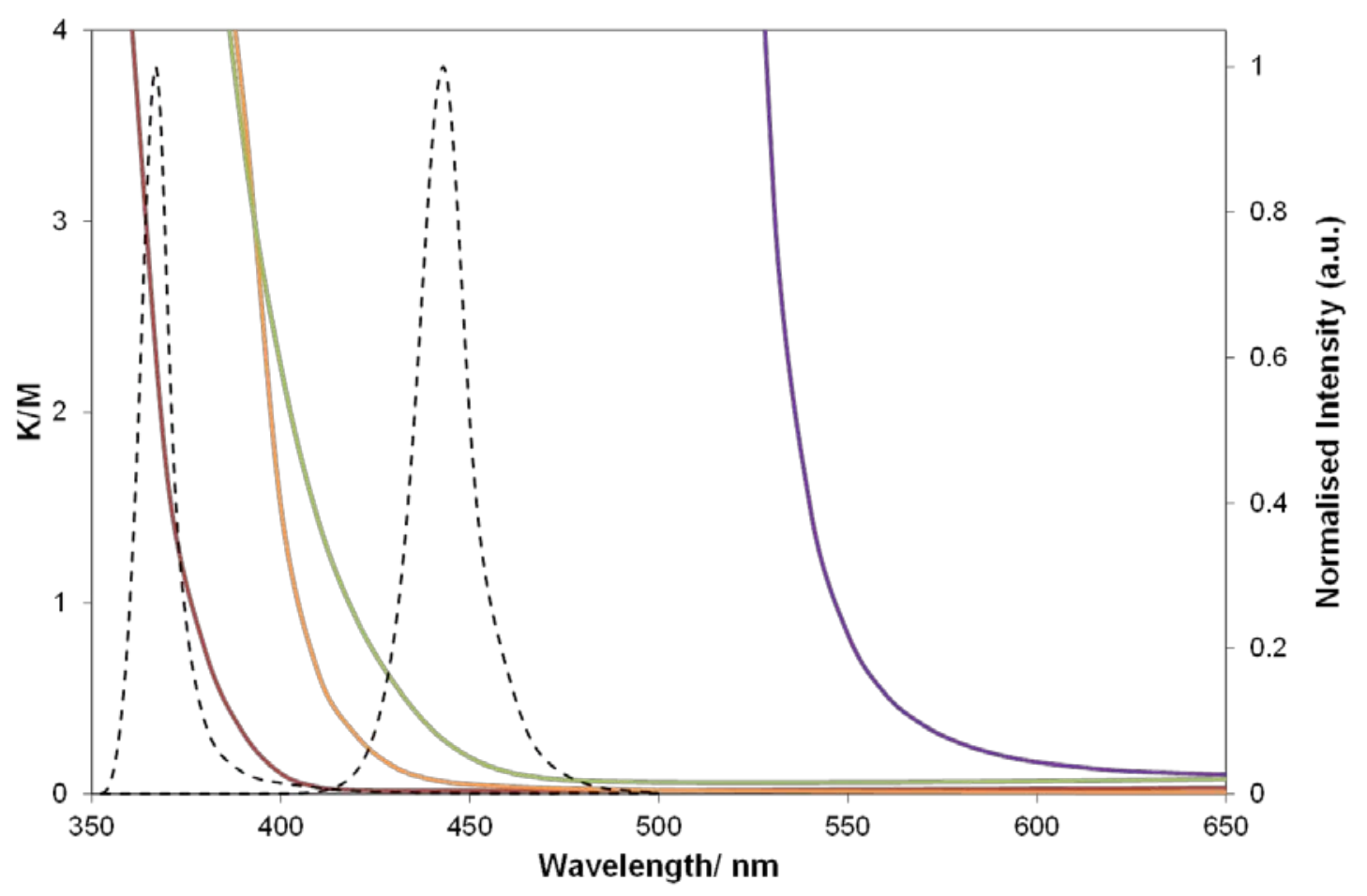

(b)

Figure 2: (a) Photographs of the semiconductor powders and their pressed discs used in this work and (b) diffuse reflectance spectra of the different neat semiconductor discs, i.e. from right to left): $\mathrm{CdS}, \mathrm{WO}_{3}, \mathrm{C}_{3} \mathrm{~N}_{4}$ and $\mathrm{TiO}_{2}$. The broken lines illustrate the emission spectra of the 455 and $365 \mathrm{~nm}$ LEDS. The intensity of each LED has been normalised to the peak LED emission output, measured with respect to power (i.e. $\mu \mathrm{W} \mathrm{cm}^{-1} \mathrm{~nm}^{-1}$ ). 


\subsection{Film disc irradiations}

The preparation of the $R z$ ink used in this work has been described elsewhere [32] and comprised: $20 \mathrm{~g}$ of 1.5\% HEC, $2 \mathrm{~g}$ glycerol and $20 \mathrm{mg} \mathrm{Rz.} \mathrm{For} \mathrm{all} \mathrm{Rz-ink-on-SC-disc} \mathrm{irradiations,} \mathrm{a}$ few drops of the Rz ink were pipetted onto the pressed semiconductor disc and spun at 2000 rpm for $30 \mathrm{~s}$. The semiconductor disc, with Rz ink film coating, was then placed $3 \mathrm{~cm}$ away from the LED and irradiated. The progress of reaction (3) was then monitored periodically by removing and photographing the ink-coated disc using a digital SLR (Canon 7D, 24-70mm f2.8 L USM lens) as a function of irradiation time. This was repeated until no further colour change was observed in the Rz ink, or after a period of $10 \mathrm{~min}$, whichever was the shorter period of time. All photographs were analysed using the free ImageJ ( $v$ 1.51d) software [33], which allowed the extraction of the RGB data from each photographed image of the disc as a function of irradiation time. This data was used to calculate the normalized red component $\left(R G B_{R}{ }^{\prime}\right)$ at each sampled irradiation time, $t$, for each disc. From a plot of this data for each disc, i.e. $\operatorname{RGB}_{R}{ }^{\prime}$ vs. $t$, a value for an associated time taken to bleach $90 \%$ of the red component of the Rz ink, i.e. $t t b(90)$, was determined. The latter parameter corresponds to the time taken to lose $90 \%$ of the blue colouration, due to $\mathrm{Rz}$ ink, as the dye is reduced to $\mathrm{Rf}$ and the reciprocal of this parameter is taken as a measure of the rate of the photocatalysed reaction (3) by the SC under test. Further details concerning this type of analysis are reported elsewhere [34]. 


\section{Results}

The recorded band positions of the semiconductor photocatalysts used in this study are illustrated in figure 3.

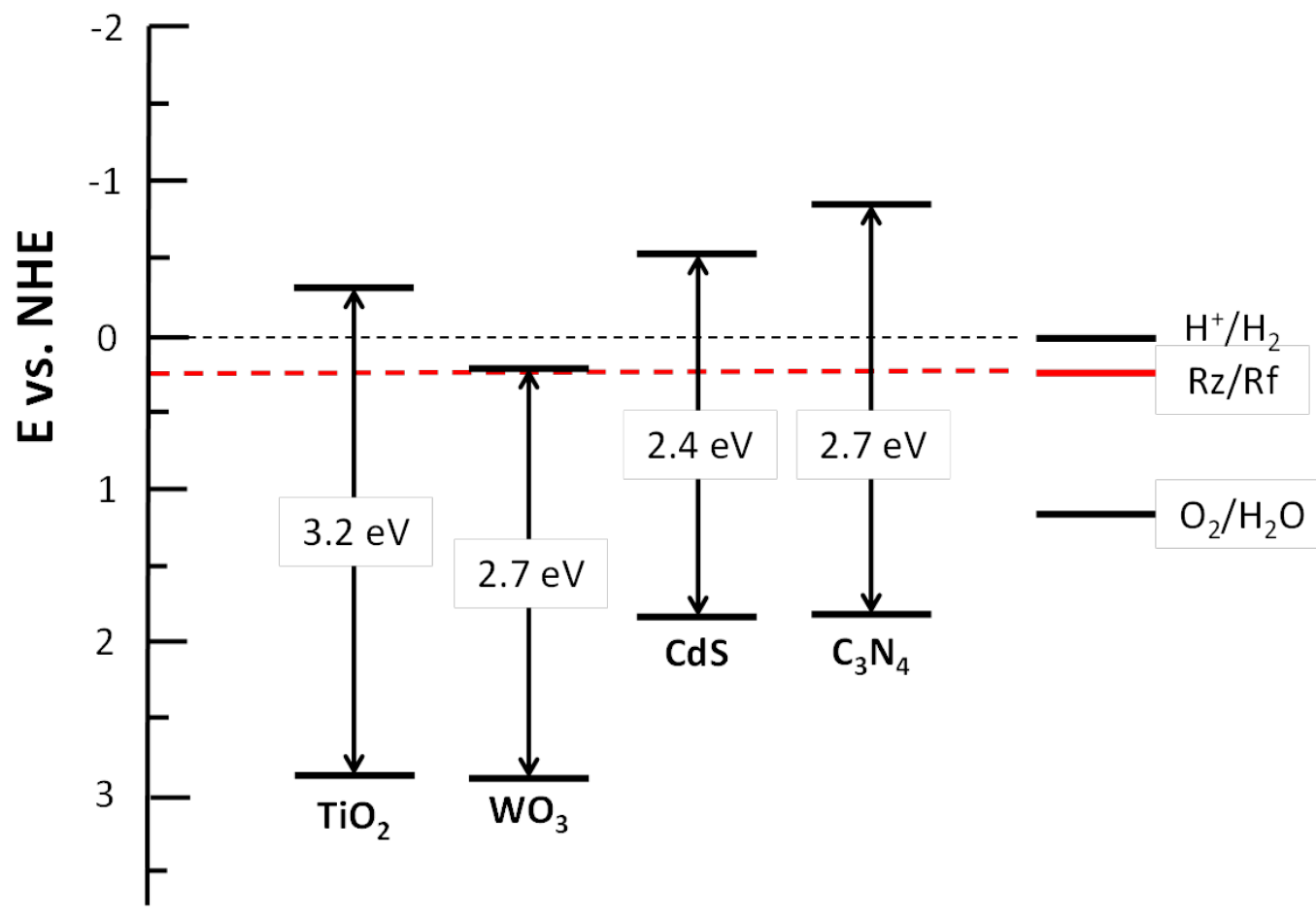

Figure 3: Band positions (at $\mathrm{pH}=0$ ) and band gaps of the semiconductors used in this work, along with the pseudo redox potential for the $\mathrm{Rz} / \mathrm{Rf}$ couple.

The reduction of $\mathrm{Rz}$ to $\mathrm{Rf}$ is an irreversible process and so the reporting of a redox potential for this couple is inappropriate, however, others [35] have estimated that $\mathrm{Rz}$ 'is reduced at potentials below $\mathrm{MB}\left[\mathrm{E}^{\circ}(\mathrm{MB} / \mathrm{LMB})=0.011\right.$ at $\left.\left.\mathrm{pH}\right]\right)$ and above $\mathrm{Rf}\left[\mathrm{E}^{\circ}(\mathrm{Rf} / \mathrm{DHRf})=-0.051 \mathrm{~V}\right.$ at $\mathrm{pH}$ 7]'. Thus, for the purposes of the schematic illustrated in figure 3, an approximate empirical value of $E^{\circ}(R z / R f)$ of ca. $-0.020 \mathrm{~V}$ at $\mathrm{pH} 7$ is indicated, which is equivalent to $0.220 \mathrm{~V}$ at $\mathrm{pH} 0$. $\mathrm{A}$ brief inspection of figure 3 , reveals that $E^{\circ}(R z / R f)$ should be more positive than the redox potentials of the conduction bands for all the different semiconductors used in this work, indicating that the reduction of $\mathrm{Rz}$, to $\mathrm{Rf}$, by the photogenerated conduction band electrons, should be thermodynamically feasible for all the SC's used here, even for $\mathrm{WO}_{3}$, which has an $E^{\circ}\left(e_{C B}{ }^{-}\right)$value of $0.17 \mathrm{~V}$. However, in order to check the feasibility of reaction (3), for all the 
semiconductors used here, the photocatalysed reaction (3) was first probed using: (i) an argonpurged, aqueous solution containing $\mathrm{Rz}\left(2 \times 10^{-5} \mathrm{M}\right)$ and glycerol (10 wt\%), and a dispersion of the photocatalysts under test, and (ii) either the UV (365 nm) or visible (455 nm) LED as the irradiation source. The results of this work are described in the next section.

\subsection{The photocatalysed reduction of $R z$ in solution}

As noted above, dispersions of each SC were irradiated with visible (455 nm LED) and UV (365 $\mathrm{nm}$ LED) radiation and, in each case, the absorption spectrum of the anaerobic Rz-containing dispersion was recorded as a function of irradiation time. A typical set of absorption spectra arising from this work is illustrated in figure 4; in this case for the visible light irradiation of a dispersion of CdS. The observed rapid changes in spectra, i.e. the disappearance of the peak at $608 \mathrm{~nm}$ (due to $\mathrm{Rz}$ ) and concomitant appearance of the peak at $585 \mathrm{~nm}$ (due to Rf) suggest that the photocatalytic reaction (3) in aqueous solution, mediated by a powdered dispersion of CdS, is rapid under visible light irradiation.

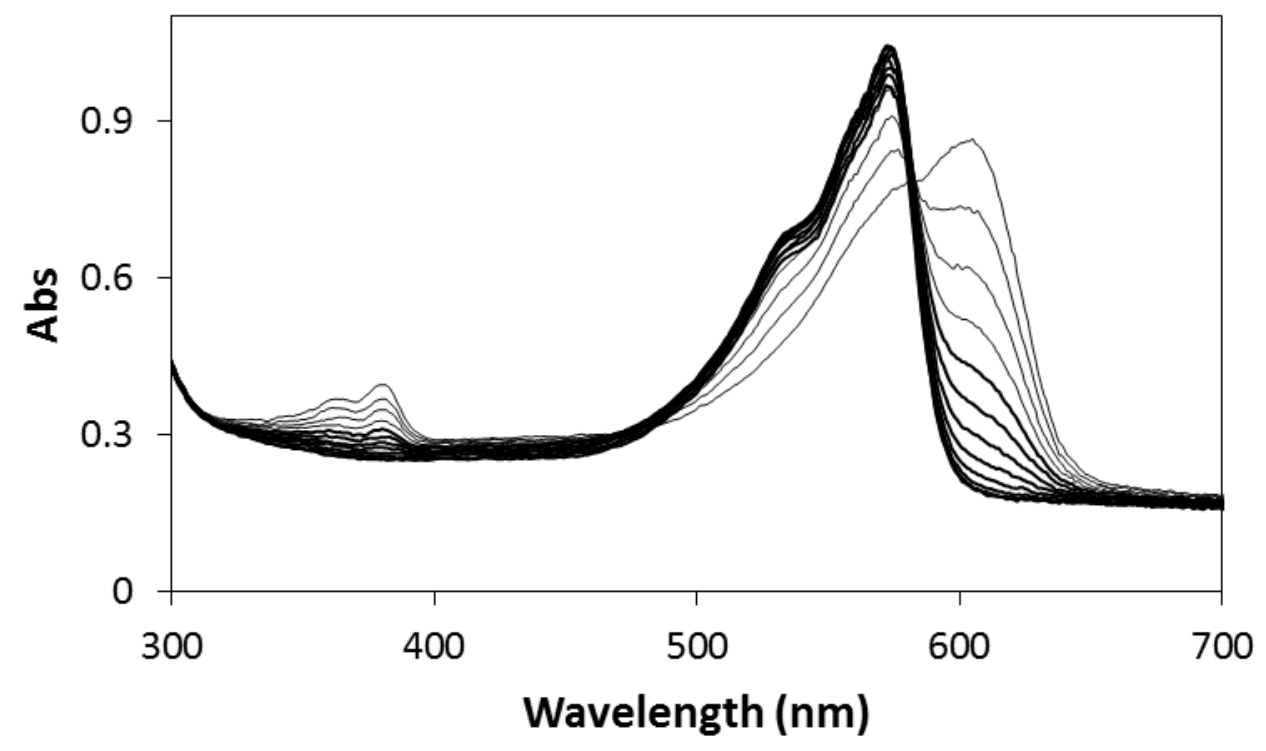

Figure 4 Recorded spectral changes for the photocatalysed reduction of $3 \mathrm{ml}$, of an argon purged, aqueous solution, containing $\mathrm{Rz}\left(2 \times 10^{-5} \mathrm{M}\right)$, glycerol $(10 \mathrm{wt} \%)$ and $0.5 \mathrm{wt} \%$ dispersion of $\mathrm{CdS}$, in a $1 \mathrm{~cm}$ cuvette. Spectra were recorded for every 20 seconds of visible $(455 \mathrm{~nm})$ light irradiation. 
Subsequent work demonstrated that all the SC photocatalysts tested, under visible and UV illumination, produced the same changes in absorption spectrum, showing they were all able to convert $\mathrm{Rz}$ to $\mathrm{Rf}$ via reaction (3), but at different rates.

A brief comparison of (i) the spectrum illustrated in figure 4 for $R z$, which is typical of all such irradiations in solution, and (ii) the emission spectra of the UV ( $355 \mathrm{~nm}$ ) and (especially) visible (455 $\mathrm{nm}$ ) LED excitation sources illustrated in figure 2, reveals that there is little or no spectral overlap between the two, i.e. both emission spectra fall in wavelength regions where the active semiconductors absorb the excitation energy, but the dye (Rz) does not. Thus, the LEDs used are operating in $\mathbf{W R ( S C )}$ 's, and so fulfil one of the key conditions for studying photocatalytic reactions involving a dye as the test substrate. The observation of no additional spectral peaks, nor significant shifts in $\lambda_{\max }$ for $\mathrm{Rz}$ and $\mathrm{Rf}$, when in the presence of any of the semiconductors, suggests no semiconductor-dye CT formation.

Note that although $\mathrm{Rz}$ is initially reduced to $\mathrm{Rf}$, via the photocatalytic reaction (3), as the irradiation progresses the $\mathrm{Rf}$ is subsequently reduced to dihydro resorufin (dH-Rf) which is colourless, via the following photocatalytic reaction:

$$
\text { Glycerol }+R f \longrightarrow \text { glyceraldehyde }+d H-R f
$$

Thus, in order to gain a measure of the overall photocatalysed reduction of $\mathrm{Rz}$, just the change in absorbance, at $608 \mathrm{~nm}, \Delta \mathrm{Abs}_{608}$, is reported here as a function of irradiation time, although, in all cases, the initial large decrease in $\Delta \mathrm{Abs}_{608}$ was found to correlate directly with the much smaller (and less easy to measure) increase in $\Delta \mathrm{AbS}_{585}$, due to $\mathrm{Rf}$ production.

The light-induced spectral changes of the type illustrated in figure 4, were recorded for each of the SCs tested, and an associated $\triangle \mathrm{Abs}_{608}$ versus irradiation time, $t$, profile extracted; the results of this work, arising from the visible light irradiation study, are illustrated in figure 5(a). From these decay profiles, it is apparent that both $\mathrm{TiO}_{2}$ and $\mathrm{SiO}_{2}$ do not show any appreciable visible light photocatalytic activity, as would be expected given their large (UV only absorbing) band gaps. These two 'blank' runs also demonstrate that the non-photocatalytic processes associated with dye photobleaching, such dye photolysis and dye photosensitization, are also negligible when using a $455 \mathrm{~nm}$ LED as the visible light source. These observations are not too 
surprising given the absorption spectra of both $\mathrm{Rz}$ and $\mathrm{Rf}$, as illustrated in figure 4, reveal that neither species absorb strongly at $455 \mathrm{~nm}$.

In contrast to the $\triangle \mathrm{Abs}_{608}$ vs. $t$ profiles for $\mathrm{TiO}_{2}$ and $\mathrm{SiO}_{2}$, the remaining $\mathrm{SCs}$ do appear to show activity with respect to the photocatalysed bleaching of $\mathrm{Rz}$ to $\mathrm{Rf}$, i.e. reaction (3), with activities in the order: $\mathrm{CdS}(0.5)>>\mathrm{WO}_{3}(1)>\mathrm{C}_{3} \mathrm{~N}_{4}(5)>>\mathrm{TiO}_{2}(0.5), \mathrm{SiO}_{2}(0.5)$, where the numbers in parenthesis refer to the different loadings used (in wt\%) so as to create dispersions with approximately the same background absorbance at $800 \mathrm{~nm}$, i.e. 0.18. If the same loading was used, the order is likely to stay the same but the differences would be more striking. In listing the order of activities here, and elsewhere, this is not to say that this would be the order found for all samples of the same semiconductors, given photocatalytic activity depends markedly on so many different parameters including: surface area, crystalline plane, defect sites and density, impurities etc.

The much lower activity of the $\mathrm{C}_{3} \mathrm{~N}_{4}$, when compared to $\mathrm{WO}_{3}$, see figure $5(\mathrm{a})$, despite the fact that the reported band gaps are the same (see figure 1), is not too surprising given the colours and diffuse reflectance spectra illustrated by these two powders are quite different (see figure 2). Thus, the relevant spectra illustrated in figure 2 show clearly that the yellow $C_{3} N_{4}$ overlaps much less well with the emission spectrum of the $455 \mathrm{~nm}$ LED, than does that of the green $\mathrm{WO}_{3}$. It follows that the above difference in rate is most probably due to the difference in spectral overlap with the $455 \mathrm{~nm}$ LED. In contrast with the $\mathrm{C}_{3} \mathrm{~N}_{4}$ and $\mathrm{WO}_{3}$ powders, the diffuse reflectance spectrum of the orange/red CdS powder overlaps significantly with the emission spectrum of the $455 \mathrm{~nm}$ LED (see figure 2) and so this SC exhibits the greatest rate for the photocatalysed reaction (3), under visible light irradiation of all the SC's tested. 

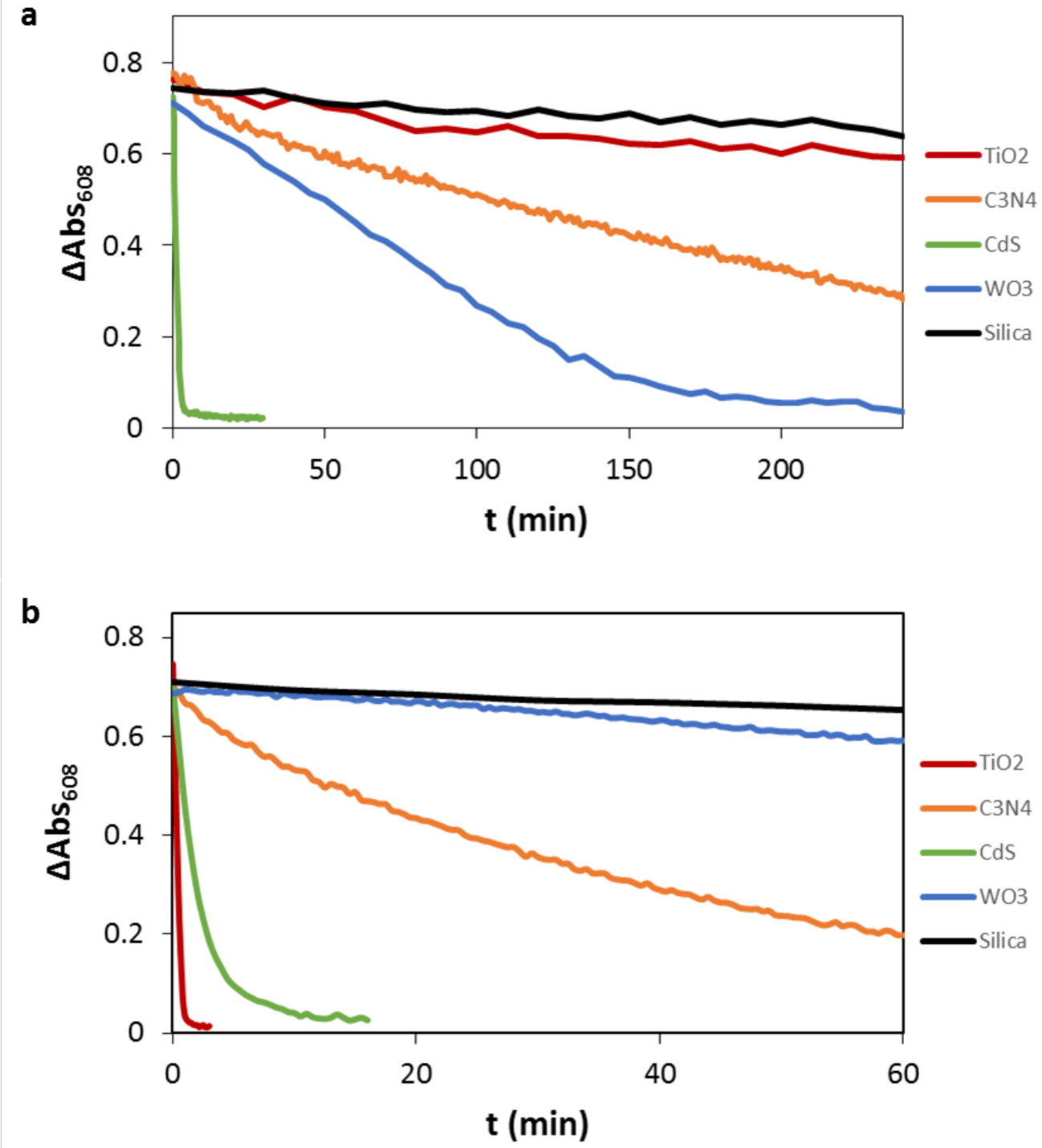

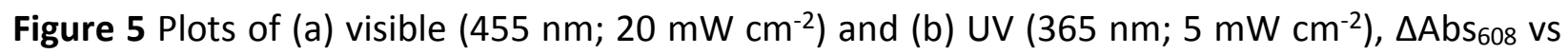
illumination time, $t$, profiles determined for the different SCs for the photocatalysed reduction of $\mathrm{Rz}$ in aqueous solution containing $10 \mathrm{wt} \%$ glycerol. The SC dispersion concentrations used for $\mathrm{TiO}_{2}, \mathrm{C}_{3} \mathrm{~N}_{4}, \mathrm{CdS}, \mathrm{WO}_{3}$ and $\mathrm{SiO}_{2}$, were: 0.05, 0.5, 0.05, 0.1 and $0.05 \mathrm{wt} \%$, respectively.

Figure $5(\mathrm{~b})$ illustrates the recorded $\Delta \mathrm{Abs}_{608}$, vs $t$, profiles, when the same set of $\mathrm{SCs}$, dispersed in an anaerobic aqueous solution of $\mathrm{Rz}$, were irradiated with UV (365 nm) light, under otherwise the same experimental conditions. In contrast to the previous (visible light) study, there is no issue of poor spectral overlap with the emission spectrum of the LED, as illustrated by the data in figure $2(\mathrm{~b})$ and the order of photocatalytic activities for reaction (3) appears to 
be: $\mathrm{TiO}_{2}(0.5)>\mathrm{CdS}(0.5)>\mathrm{C}_{3} \mathrm{~N}_{4}(5)>>\mathrm{WO}_{3}(1)>\mathrm{SiO}_{2}(0.5)$; figures in parenthesis refer to semiconductor loading (in wt\%). Note that the UV decay profiles were recorded over a much shorter period of time than the visible light irradiations (i.e. 60 instead of $240 \mathrm{~min}$ ), because the activity of $\mathrm{TiO}_{2}$ was so high, even though the UV irradiance was 4 times lower, i.e. 5, instead of $20 \mathrm{~mW} \mathrm{~cm}^{-2}$. It appears reasonable, given the noted high photocatalytic activity of P25 $\mathrm{TiO}_{2}$, that this $\mathrm{SC}$ is the most active of all those tested, and that $\mathrm{SiO}_{2}$, with its bandgap of $9.3 \mathrm{~V}$, appears, once again, to be inactive.

From a brief inspection of the decay profiles illustrated in figure 4, it might be thought odd that $\mathrm{WO}_{3}$ appears so much lower in activity (rate $=1.6 \times 10^{-3}$ absorbance per min), given the comparatively striking activity (rate $=4.3 \times 10^{-3}$ absorbance per $\min$ ) it exhibited when illuminated with visible (455 nm) light. However, the latter low rate is consistent with the UV irradiance used, which was four times lower than the visible irradiance, i.e. 5 instead of $20 \mathrm{~mW}$ $\mathrm{cm}^{-2}$. From the results in figure $5(\mathrm{~b}), \mathrm{C}_{3} \mathrm{~N}_{4}$ appears to have a greater photocatalytic activity than $\mathrm{WO}_{3}$, presumably because it - like $\mathrm{WO}_{3}$-absorbs all incident UV light photons, due to its significant spectral overlap with the emission spectrum of the UV LED, and its much greater surface area (see Table 1). Note, however, if the same loading for each semiconductor was used here, the order of activities would most likely be different. But, overall, the relative rates of reaction (3) for the different SC's tested, when dispersed in aqueous solution, under visible and UV irradiation appear consistent with what we know about these SCs.

\subsection{The photocatalysed reduction of Rz by pressed semiconductor films}

In almost all previous work carried out on semiconductor films, such as self-cleaning glass and paint, using photocatalyst indicator inks, the Rz ink coating on the semiconductor film under test was irradiated in air [32]. This is in sharp contrast with all the work carried out in aqueous solution described above which was carried out under $\mathrm{O}_{2}$-free conditions.

Typically, using a commercial sample of self-cleaning glass, under aerobic conditions, the transformation in colour of an Rz ink (blue to pink) is usually effected within 10 minutes or less, 
using a UV irradiance of ca. $1 \mathrm{~mW} \mathrm{~cm}^{-2}$. However, it is known [32] that the $\mathrm{O}_{2}$ present in air is able to compete with the Rz for reduction by the photogenerated electrons, i.e.

$$
\mathrm{O}_{2}+\mathrm{TiO}_{2}\left(\mathrm{e}^{-}\right) \stackrel{\mathrm{SC}}{\mathrm{hv} \geq \mathrm{E}_{\mathrm{bg}}} \mathrm{O}_{2}^{-}+\mathrm{TiO}_{2}
$$

and so effect a decrease in the rate of reaction (3), typically by ca. $40 \%$ for $\mathrm{TiO}_{2}$ self-cleaning films; although, to be able to conduct the test in air makes it much more useful and easier to effect. Fortunately, since reaction (5) is a constant, competitive background kinetic feature, it has been shown that it is still possible to correlate the activity of a SC film as measured using an Rz paii in air with that measured using a more traditional method, such as the oxidation of a film of stearic acid [23] or MB in solution [36]. Thus, in this work, the initial study of the pressed films of the SCs, illustrated in figure 2, was carried out in air. Disappointingly, under these conditions, of all the SCs tested, only $\mathrm{TiO}_{2}$, under UV irradiation, exhibited a striking, rapid colour change, (blue to pink), as illustrated in figure 6(a) below, a photographic record of the Rz ink-coated discs as a function of irradiation time, for the $\mathrm{TiO}_{2}$ and $\mathrm{SiO}_{2}$ discs only; the latter serving as a blank. These results show that in air, only $\mathrm{TiO}_{2}$ demonstrates a sufficiently high enough activity for $\mathrm{Rz}$ reduction, i.e. reaction (3), so as to be able to compete with reaction (5) and effect the blue to pink colour change associated with the reduction of Rz to Rf.

It follows from the above findings that to be able to effect reaction (3) using films of SC's other than $\mathrm{TiO}_{2}$, the reaction needs to be conducted under anaerobic conditions. Obviously, this can be achieved by sparging the system with argon, however, this is not particularly easy, nor practical. Instead, a simpler and quicker method that achieves the same result is to cover the surface of the ink-coated disc with a clear adhesive tape, such as Sellotape ${ }^{\mathrm{TM}}$, since the latter acts as a significant diffusion barrier to ambient air [37]. This approach was used here to probe the activities of the different SC discs, using visible and UVA light and the results of this work are illustrated in figures $6(\mathrm{~b})$ and $6(\mathrm{c})$, respectively. However, for reasons that remain unclear, even with this $\mathrm{O}_{2}$-barrier coating, an $\mathrm{Rz}$ ink film on $\mathrm{C}_{3} \mathrm{~N}_{4}$, under either UV or visible light 
irradiation, exhibited no significant change in colour and so the unchanging photographs recorded for this film as a function of $t$ have been omitted from figures $6(b)$ and $6(c)$.

\section{(a)}

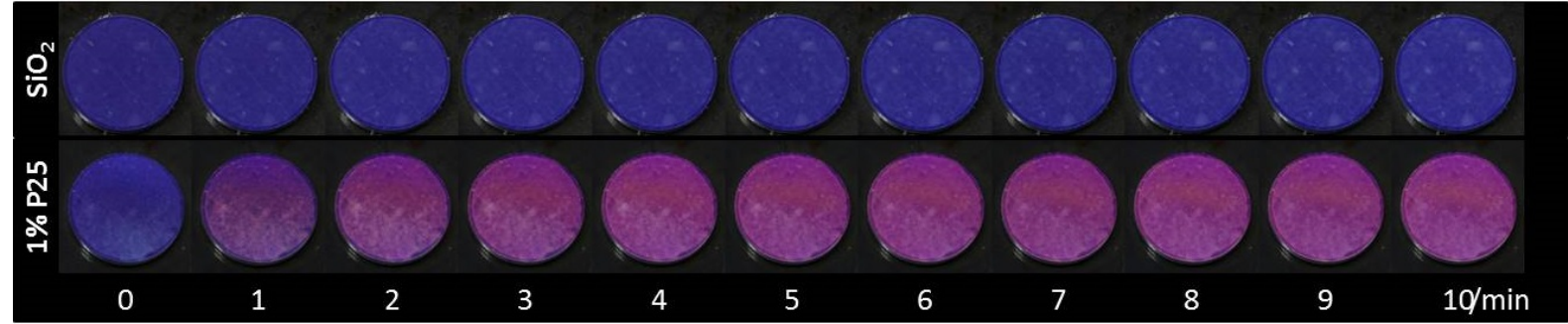

(b)

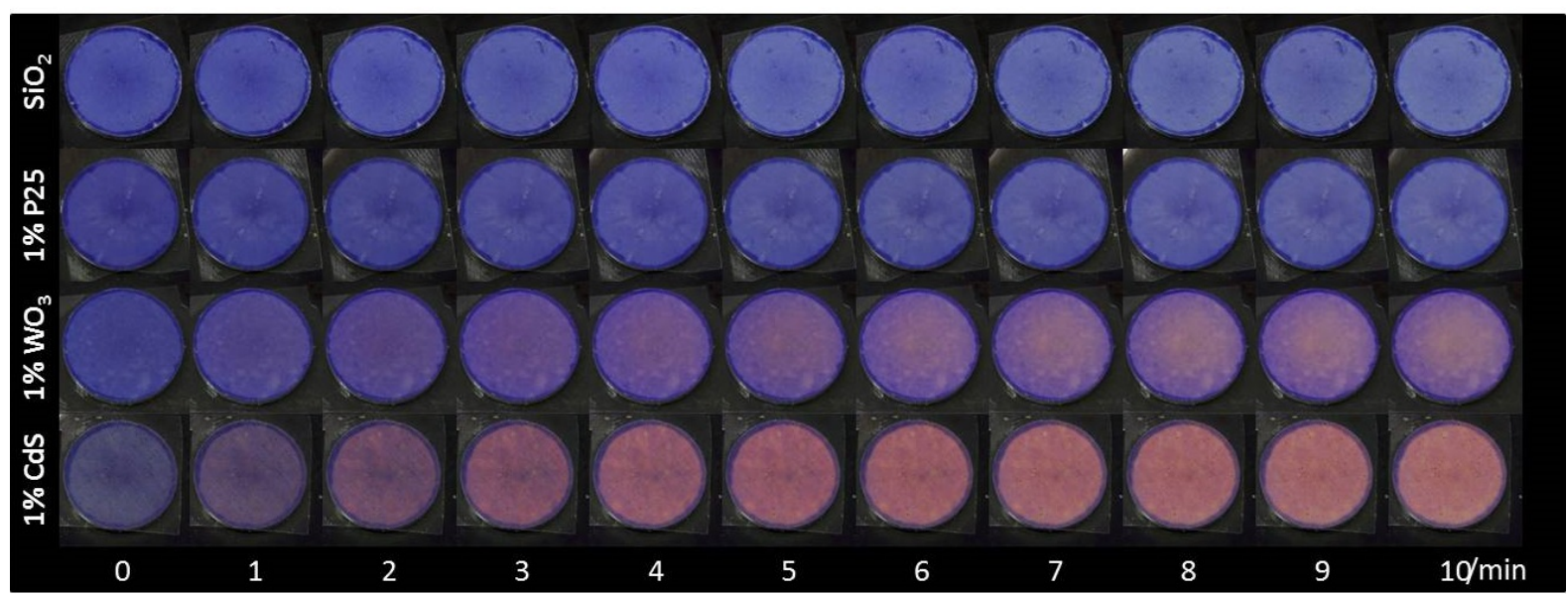

(c)

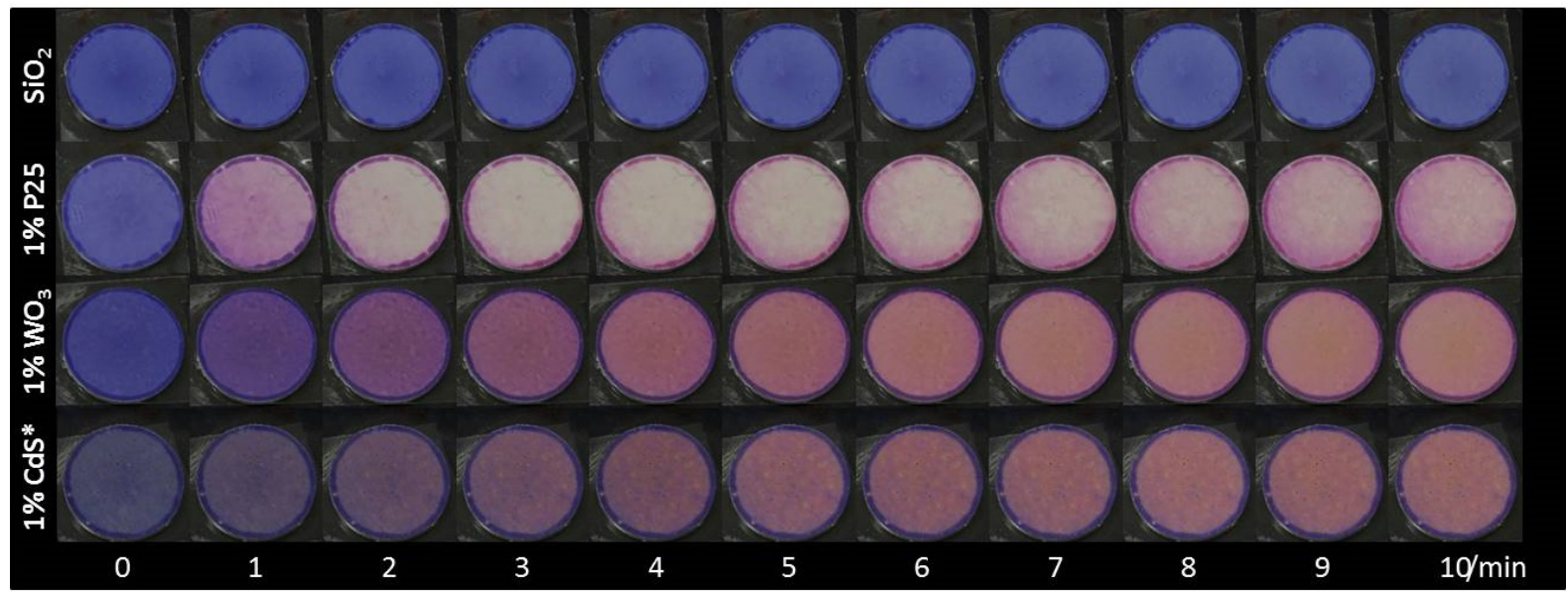

* CdS irradiations performed at $5.5 \mathrm{~mW} \mathrm{~cm}^{-2}$

Figure 6 Photographs of the colour change of the Rz ink on pressed disks upon irradiation under (a) $1.5 \mathrm{~mW} \mathrm{~cm}^{-2}$ UVA ( $365 \mathrm{~nm}$ ) (in air), (b) $14 \mathrm{~mW} \mathrm{~cm}^{-2}$ visible (455 nm) (under Sellotape ${ }^{\mathrm{TM}}$ ), and (c) $1.5 \mathrm{~mW} \mathrm{~cm}^{-2}$ UVA (365 nm) (under Sellotape ${ }^{\mathrm{TM}}$ ). 
Using the images in figures $6(\mathrm{~b})$ and $6(\mathrm{c})$, plots of the variation in the normalized red component of the digital image of the films, $\mathrm{RGB}_{R}{ }^{\prime}$ [23], which provides an effective measure of any change in the blue colouration, as a function of irradiation time $t$, were generated for all the films and the results are illustrated for the visible (455 nm) and UV (365 nm) irradiations, in figures $7(a)$ and $7(b)$, respectively.
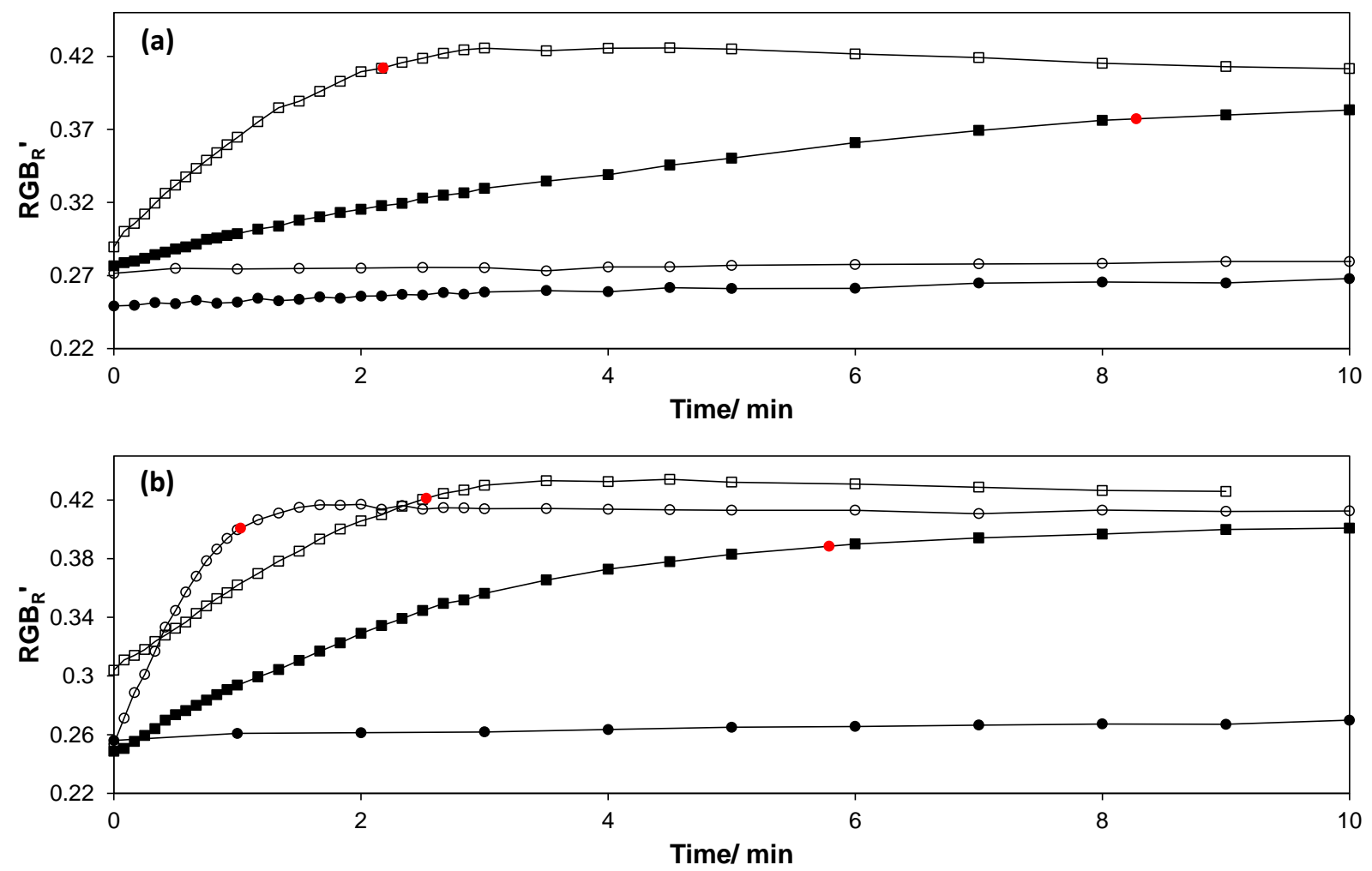

Figure 7 Plot of the variation of the normalised red component $\left(R G B_{R}{ }^{\prime}\right)$ vs. time from digital photographs (see figures 6(b) and 6(c)) for the irradiation of the Rz ink on each of the pressed

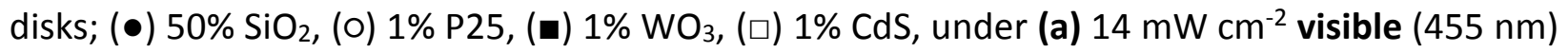
light, and (b) $1.5 \mathrm{~mW} \mathrm{~cm}^{-2}$ UVA (365 nm). All irradiations were performed under Sellotape ${ }^{\mathrm{TM}}$. The red dots highlight the calculated values for the time to bleach $90 \%$ of the red component of the ink, i.e. the $t \mathrm{tb}(90)$ for the different SCs; these were: 1, 2.6 and $5.8 \mathrm{~min}$ for $\mathrm{TiO}_{2}$, CdS and $\mathrm{WO}_{3}$, respectively, under UV illumination and 2.2 and $5.8 \mathrm{~min}$ for $\mathrm{CdS}$ and $\mathrm{WO}_{3}$, respectively, under visible illumination. 
From the images of the ink films as a function of visible irradiation time illustrated in figure 6(b), it appears that tape-covered pressed films of the $\mathrm{TiO}_{2}$ and $\mathrm{SiO}_{2}$ powders under visible (455 $\mathrm{nm} ; 14 \mathrm{~mW} \mathrm{~cm}^{-2}$ ) light irradiation showed little change in colour over a 10 minute irradiation period, which is not too surprising given neither absorb visible light. The associated $\mathrm{RGB}_{\mathrm{R}}{ }^{\prime} \mathrm{vs.} t$ for the same films, illustrated in figure $7(a)$, confirm this impression gleaned from the photographs, although, since the profiles have small positive gradients, a slight bleaching of the $\mathrm{Rz}$ dye is indicated for both $\mathrm{SiO}_{2}$ and $\mathrm{TiO}_{2}$, suggesting that a very slow photobleaching of the $\mathrm{Rz}$ dye does occur, due to some dye photolysis most likely, even though Rz absorbs only very weakly at $455 \mathrm{~nm}$, see figure 4 .

In contrast to $\mathrm{SiO}_{2}$ and $\mathrm{TiO}_{2}$, visible light irradiation of $\mathrm{CdS}$ and $\mathrm{WO}_{3}$ pressed discs produced, within $10 \mathrm{~min}$, the colour change expected for the photocatalysed reduction of Rz (blue) to Rf (pink) and the subsequent further reduction of the latter to dihydro-resorufin, $\mathrm{dH}-\mathrm{Rf}$, which is colourless. The observed (i.e. photographed) colour changes appear different for these two SC due to the original underlying colour of the semiconductor pressed disc, illustrated in figure 2 , although, in both cases, diffuse reflection spectroscopy confirms the intermediate generation of $\mathrm{Rf}$, before this is, in turn, reduced to $\mathrm{dH}-\mathrm{Rf}$, vide infra.

A brief examination of both the photographs illustrated in figure $6(b)$ and the associated $R G B_{R}{ }^{\prime}$ vs. $t$ profiles, illustrated in figure $7(\mathrm{a})$, reveals that $\mathrm{CdS}$ is much more active than $\mathrm{WO}_{3}$ as a visible light catalyst for the reduction of Rz to Rf. This finding is not too surprising, and similar to that found from the work carried out in solution, given its much bigger spectral overlap with the emission spectrum of the $455 \mathrm{~nm}$ LED (see figure 2). The overall order in activity, after omitting $\mathrm{C}_{3} \mathrm{~N}_{4}$, is: $\mathrm{CdS}>\mathrm{WO}_{3} \gg \mathrm{TiO}_{2}, \mathrm{SiO}_{2}$, which is the same as was found in the Rz solution study, see section 3.1.

The images of the ink films as a function of $\mathbf{U V}\left(365 \mathrm{~nm} ; 1.5 \mathrm{~mW} \mathrm{~cm}^{-2}\right)$ irradiation time are illustrated in figure $6(\mathrm{c})$ and show, for a tape-covered, $\mathrm{Rz}$ ink film coated sample of $\mathrm{SiO}_{2}$, that there is little, if any, change in the colour of the original ink as might be expected, given its insulator nature. In contrast, for the $\mathrm{TiO}_{2}$ film, within 1 min of irradiation not only has all the $\mathrm{Rz}$ been converted to $\mathrm{Rf}$, but also much of the $\mathrm{Rf}$ has been subsequently reduced to $\mathrm{dH}-\mathrm{Rf}[20]$. It is also clear from the photographs in figure $6(\mathrm{c})$ and the associated $R G B_{R}^{\prime}$ vs. $t$ profiles, 
illustrated in figure $7(\mathrm{~b})$, that the order of activity: $\mathrm{TiO}_{2}>\mathrm{CdS}>\mathrm{WO}_{3}$ is the same as found in the Rz solution study, see section 3.1 .

Finally, figure 8 provides two typical illustrations of the recorded changes in the diffuse reflectance spectrum of the Sellotape ${ }^{\mathrm{TM}}$-coated, Rz ink film on (a) CdS (visible irradiation) and (b) $\mathrm{TiO}_{2}$ (UV irradiation) pressed discs. In both, the conversion of the blue $\mathrm{Rz}(610 \mathrm{~nm})$ to pink $\mathrm{Rf}(580 \mathrm{~nm})$ is clear as is the subsequent reduction of $\mathrm{Rf}$ to $\mathrm{dH}-\mathrm{Rf}$, a pink to colourless transition.
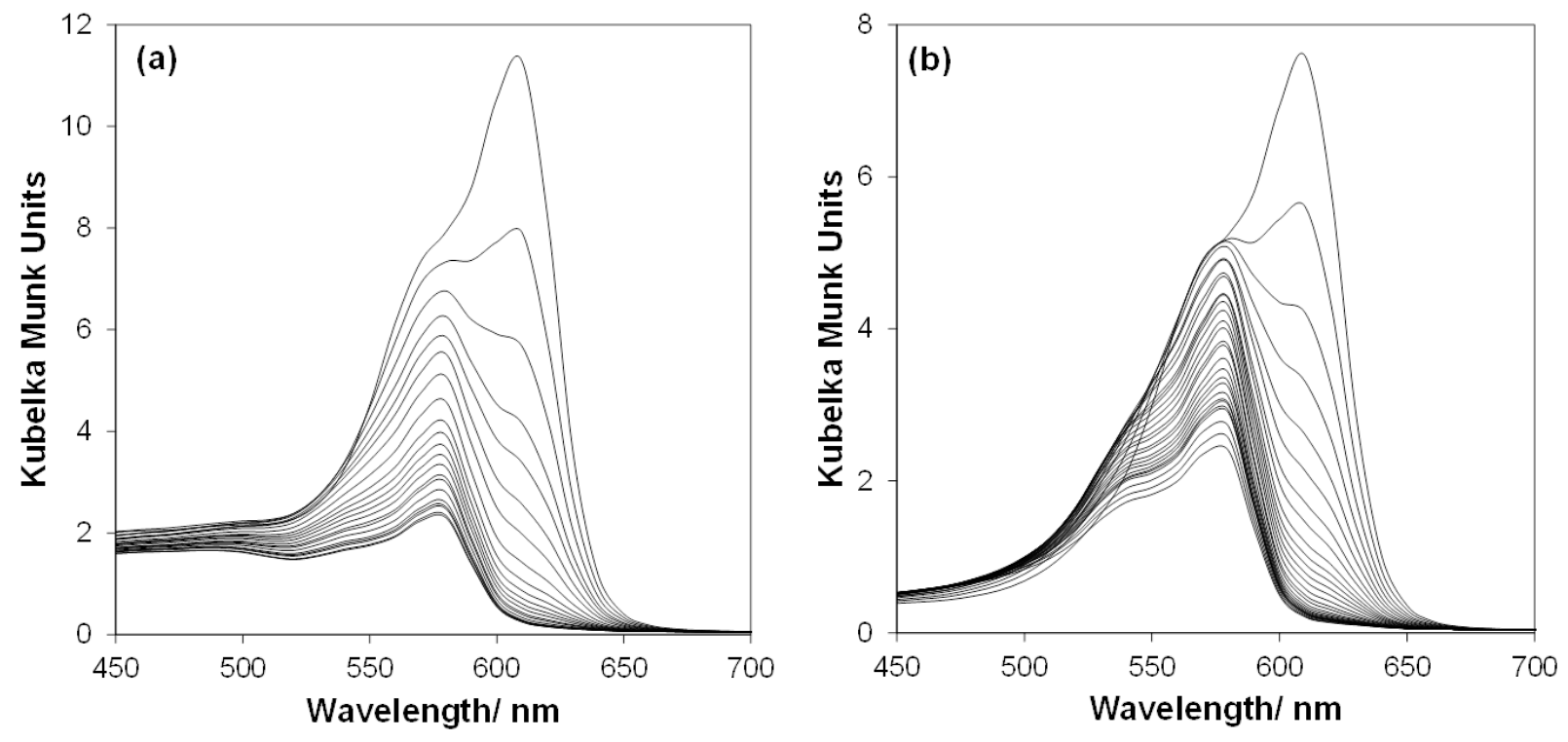

Figure 8 Change in the diffuse reflectance spectra of; (a) Rz on a 1\% CdS disc under visible light (455 nm, $14 \mathrm{~mW} \mathrm{~cm}^{-2}$ ) at 10 s intervals, and (b) Rz on a 1\% P25 disc under UVA light (365 nm, $1.5 \mathrm{~mW} \mathrm{~cm}^{-2}$ ) at $5 \mathrm{~s}$ intervals. All irradiations were performed under tape and monitored using a hand-held spectrophotometer (Konica Minolta, CM-2500d). $\lambda_{\max }(\mathrm{Rz})=610 \mathrm{~nm}(608 \mathrm{~nm}$ in solution), and $\lambda_{\max }(\mathrm{Rf})=580 \mathrm{~nm}$ (582 $\mathrm{nm}$ in solution).

\subsection{Dye photostability studies using $617 \mathrm{~nm}$ light}

This work seeks to utilise an Rz-paii to probe, amongst other things, the visible light activity of established visible light photocatalysts, and, in so doing, to use excitation light that only the semiconductor, and not the dye, can absorb, such as 365 and $455 \mathrm{~nm}$ light, i.e. WR(SC) light. However, it is instructive to probe what happens when the two different systems ('SC+ Rz/glycerol/water' and 'SC 
+ Rz-paii') are exposed to light which the semiconductors employed in this study cannot absorb, but the dye can, namely: $617 \mathrm{~nm}$ light. Since most of these irradiations are carried out under anaerobic conditions, it seems unlikely a traditional dye-photosensitised process, as summarised by reaction (2), can occur, and thus any bleaching is most likely due to dye photolysis.

In aqueous solution, under anaerobic conditions, using the usual dispersions of $\mathrm{SiO}_{2}, \mathrm{TiO}_{2}, \mathrm{CdS}, \mathrm{WO}_{3}$, under irradiation with $617 \mathrm{~nm}$ light $\left(10 \mathrm{~mW} \mathrm{~cm}^{-2}\right)$ all solutions were found to bleached very slowly, whilst exhibiting no evidence of Rz formation, i.e. the initial blue colouration due to Rz gradually faded. A typical spectral decay profile is illustrated in Figure 9(a) for the Rz/CdS/glycerol/water (concentrations same as in figure 4), and similar profiles, and kinetics, were recorded for all the other SCs/insulator. From this work the half-life for dye photobleaching, $t_{1 / 2}$, was found to be $4.3 \pm 1 \mathrm{~h}$ for all the oxides. Similar kinetics with a similar $t_{1 / 2}$ value for all the SCs/insulator is what would be expected if the degradation process was due to a dye dependent (but semiconductor independent) degradation process, like dye photolysis, and opposite to that expected if it were due to dye photosensitisation. In contrast, for the same system, but using: 'visible' light ( $455 \mathrm{~nm}, 20 \mathrm{~mW} \mathrm{~cm}^{-2}$ ), the rates were found to be much faster and to vary greatly (depending on how well if, at all, the SC absorbed the incident UV light), revealing $t_{1 / 2}$ values of: $0.02,1.36,9.3$ and $16 \mathrm{~h}$ for $\mathrm{CdS}, \mathrm{WO}_{3}, \mathrm{TiO}_{2}$ and $\mathrm{SiO}_{2}$, respectively and, in which $\mathrm{Rf}$ generation was clearly observed, in the first two cases, as illustrated in figure 4 for $\mathrm{CdS}$. The observation of $t_{1 / 2}$ values that vary depending upon the amount of $(455 \mathrm{~nm})$ light absorbed by these semiconductors, is what would be expected for a photocatalytic process. The very low rate recorded for $\mathrm{TiO}_{2}\left(\right.$ and $\left.\mathrm{SiO}_{2}\right)$ in the $455 \mathrm{~nm}$ irradiation study is because neither the $\mathrm{TiO}_{2}$ (or $\mathrm{SiO}_{2}$ ), nor the $\mathrm{Rz}$, absorb strongly at this wavelength, in contrast to $\mathrm{CdS}$ and - to a lesser extent - $\mathrm{WO}_{3}$.

Sellotape ${ }^{\mathrm{TM}}$-covered, i.e. anaerobic, Rz pressed semiconductor films of $\mathrm{SiO}_{2}, \mathrm{TiO}_{2}, \mathrm{CdS}, \mathrm{WO}_{3}$, were also irradiated with $617 \mathrm{~nm}$ light $\left(10 \mathrm{~mW} \mathrm{~cm}^{-2}\right)$ and, once again, the dye was seen to bleach slowly, at approximately the same rate, with a $t$ tb(90) ca. $40 \mathrm{~min}$, whilst exhibiting no evidence of Rz formation. Figure 9(b) illustrates a typical diffuse reflectance spectrum decay profile for an Rz-paii on CdS pressed disc, recorded as a function of time, upon irradiation with $617 \mathrm{~nm}$ light, which is in marked contrast to that illustrated in figure 8(a), in which $455 \mathrm{~nm}$ light was used as the excitation source. From Figure 7 we see that the measured $t t b(90)$ values for $\mathrm{CdS}$ and $\mathrm{WO}_{3}$ (irradiated with $455 \mathrm{~nm}$ light) were 2.2 and 5.8 min, respectively, and so much faster than the average value of $40 \mathrm{~min}$ found for all the SCs/insulator when irradiated with $617 \mathrm{~nm}$ light. As with the solution work, the bleaching of the $\mathrm{Rz}_{\text {paii }}$ on $\mathrm{TiO}_{2}$ (or 
$\mathrm{SiO}_{2}$ ) using $455 \mathrm{~nm}$ light was incredibly slow $(t t b(90)>8 \mathrm{~h})$ because neither the $\mathrm{TiO}_{2}\left(\right.$ or $\left.\mathrm{SiO}_{2}\right)$ nor the Rz absorb strongly at $455 \mathrm{~nm}$.

The results of the above work suggest that when either of the 'SC+Rz/glycerol/water' and 'SC + Rz-paii' systems are irradiated with $617 \mathrm{~nm}$ light, which the dye absorbs strongly but the SCs do not, the dye is bleached slowly, most likely due to a photolytic, rather than dye-photosensitised, process. At no time is there any evidence that $\mathrm{Rf}$ is produced as part of this slow degradation process. These results suggest strongly that the previous irradiations, conducted using 365 and $455 \mathrm{~nm}$ light, in which $\mathrm{Rf}$ is rapidly generated, were photocatalytic in nature, which is not surprising since they utilised light that the SC photocatalysts involved absorbed strongly, but the dye did not.
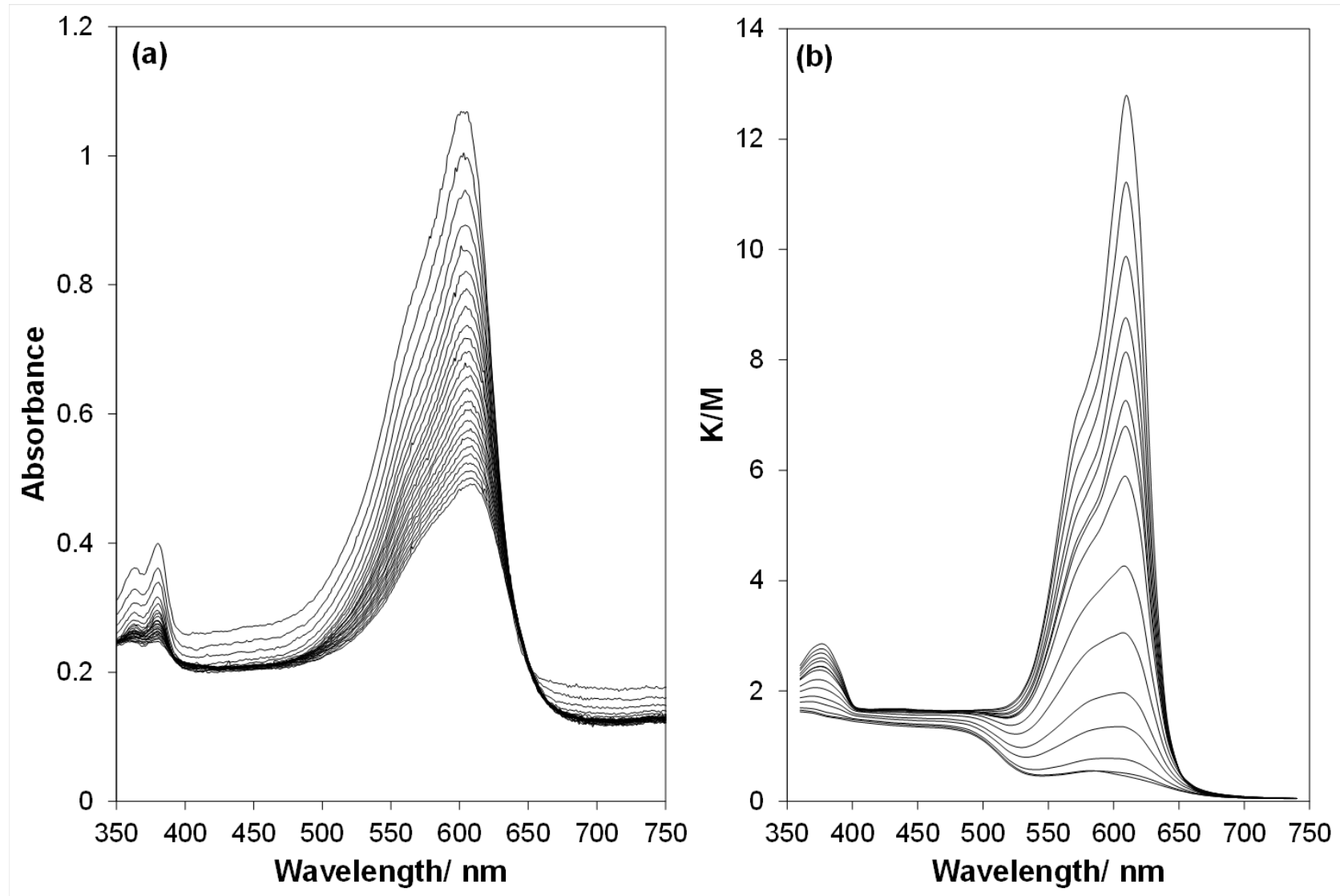

Figure 9: Using $617 \mathrm{~nm}$ light $\left(10 \mathrm{~mW} \mathrm{~cm}^{-2}\right)$ : (a) change in absorption spectrum recorded under otherwise the same $\mathrm{CdS} / \mathrm{Rz} /$ glycerol/water system as reported in figure 4, each spectrum recorded every 30 min and (b) change in DRS, absorption spectrum recorded under otherwise the same 'CdS + Rzpaii' system as reported in figure $8(a)$; the spectra were recorded after the following irradiation times (top to bottom): 0, 1, 2, 3, 4, 5, 7, 10, 15, 20, 25, 30, 40, 50, 60 min. 
These latter findings help highlight the need, when using dyes to assess the activities of photocatalysts, to use light sources that provide: (i) only a narrow range of wavelengths, such as LEDs, and (ii) radiation that is NOT absorbed significantly (preferably not at all) by the dye itself. Failure to observe (i) and (ii) may easily lead to mistaken claims of photocatalytic activity. In addition, even if the degree of spectral overlap between the absorption spectrum of the dye and the emission spectrum of the light source is small, as in the case of Rz and the 455 and 365 $\mathrm{nm}$ LED light sources, the longer the irradiation time and higher the irradiance, the more likely some, if not all the observed colour change will be due to dye photodegradation, rather than photocatalysis.

\section{Conclusions}

A variety of semiconductor photocatalyst materials, i.e. $\mathrm{TiO}_{2}, \mathrm{CdS}, \mathrm{WO}_{3}$ and $\mathrm{C}_{3} \mathrm{~N}_{4}$, when used as a dispersion in deaerated, aqueous solution, appear able to mediate the UV (365 $\mathrm{nm}$ ) photocatalysed reduction of $\mathrm{Rz}$ to $\mathrm{Rf}$ by glycerol, i.e. reaction (3). Under the same conditions, but using visible $(455 \mathrm{~nm})$ light, the same reaction is promoted by the visible-light absorbing semiconductors, $\mathrm{CdS}, \mathrm{WO}_{3}$ and $\mathrm{C}_{3} \mathrm{~N}_{4}$. When mixed with $\mathrm{SiO}_{2}$ and PTFE powder and pressed as discs, and covered with Sellotape ${ }^{\mathrm{TM}}$ to exclude ambient $\mathrm{O}_{2}$, the $\mathrm{C}_{3} \mathrm{~N}_{4}$ photocatalyst exhibited little activity under UV or visible irradiation, for reasons that remain unclear, although the other semiconductors, i.e. $\mathrm{TiO}_{2}, \mathrm{CdS}, \mathrm{WO}_{3}$, showed the same order activity as when they were used in aqueous solution. Thus, for the established $\mathrm{SC}$ photocatalysts, like $\mathrm{TiO}_{2}, \mathrm{CdS}$ and $\mathrm{WO}_{3}$, the tape-covered, Rz paii film on pressed discs method appears to work using either UV (365 nm) radiation or visible $(455 \mathrm{~nm})$ light. The latter results represent the first example of the successful use of an Rz paii for probing the activity of visible-light absorbing photocatalysts and of semiconductor powders, as opposed to films, in general. 


\section{References}

[1] P. Pichat, Photocatalysis and water purification from fundamentals to recent applications, 1st edn, Wiley-VCH, Germany, 2013.

[2] A. Mills, S. Lee, A web-based overview of semiconductor photochemistry-based current commercial applications, J Photochem. Photobiol. A: Chem. 152 (2002) 233-247.

[3] A. Mills, C. O'Rourke, K. Moore, Powder semiconductor photocatalysis in aqueous solution: an overview of kinetics-based reaction mechanisms, J. Photochem. Photobiol. A: Chem., 310 (2015) 66-105.

[4] Y. Ohko, Y. Nakamura, N. Negishi, S. Matsuzawa, K. Takeuchi, Photocatalytic oxidation of nitrogen monoxide using $\mathrm{TiO}_{2}$ thin films under continuous UV light illumination, J. Photochem. Photobiol. A: Chem. 205 (2009) 28-33.

[5] A. Mills, C. Hill, P.K.J. Robertson, Overview of the current ISO tests for photocatalytic materials, J. Photochem. Photobiol. A: Chem. 237 (2012) 7-23.

[6] ISO 10678. Fine ceramics (advanced ceramics, advanced technical ceramics) -Determination of photocatalytic activity of surfaces in an aqueous medium by degradation of methylene blue, ISO, Geneva, 2010

[7] ISO 22197-1. Fine ceramics (advanced ceramics, advanced technical ceramics) -- Test method for air-purification performance of semiconducting photocatalytic materials -- Part 1: Removal of nitric oxide, ISO, Geneva, 2007.

[8] K. Rajeshwar, M. E. Osugi, W. Chanmanee, C. R. Chenthamarakshan, M.V. B. Zanoni, P. Kajitvichyanukul and R. Krishnan-Ayer, J. Photochem. Photobiol. C. 9 (2008) 171-192.

[9] J.C. Cardoso, G.G. Bessegato and M.V.B. Zanoni, Efficiency comparison of ozonation, photolysis, photocatalysis and photoelectrocatalysis methods in real textile wastewater decolorization, Wat. Res. 98 (2016) 39-46.

[10] X. Feng, S. Zhu and H. Hou, Investigation of $207 \mathrm{~nm}$ UV radiation for degradation of organic dye in water, Water SA, 32 (2006) 43-48. 
[11] M. Rochkind, S. Pasternak and Y. Paz, Using Dyes for Evaluating Photocatalytic Properties: A Critical Review, Molecules, 20 (2015) 88-110.

[12] T. Wu, G. Liu, J. Zhao, H. Hidaka and N. Serpone, Photoassisted Degradation of Dye Pollutants. V. Self-Photosensitized Oxidative Transformation of Rhodamine B under Visible Light Irradiation in Aqueous $\mathrm{TiO}_{2}$ Dispersions, J. Phys. Chem. B, 102 (1998) 5845-5851.

[13] X. Yan, T. Ohno, K. Nishijima, R. Abe and B. Ohtani, Is methylene blue an appropriate substrate for a photocatalytic activity test? A study with visible-light responsive titania, Chem. Phys. Letts. 429 (2006) 606-610.

[14] B. Ohtani, Hidden but Possibly Fatal Misconceptions in Photocatalysis Studies: A Short Critical Review, Catalysis, 6 (2016) 192-197.

[15] I. A. Jankovic, Z.V. Saponjic, E.S. Dzunuzovic and J. M. Nedljkovic, New Hybrid Properties of $\mathrm{TiO}_{2}$ Nanoparticles Surface Modified With Catecholate Type Ligands, Nanoscale Res. Lett., 5 (2010) 81-88.

[16] S. Kim and W. Choi, Visible-Light-Induced Photocatalytic Degradation of 4-Chlorophenol and Phenolic Compounds in Aqueous Suspension of Pure Titania: Demonstrating the Existence of a Surface-Complex-Mediated Path, J. Phys. Chem. B, 109 (2005) 5143-5149.

[17] N. Wang, L. Zhu, Y. Huang, Y. She, Y. Yu and H. Tang, Drastically enhanced visible-light photocatalytic degradation of colorless aromatic pollutants over $\mathrm{TiO}_{2}$ via a charge-transfercomplex path: A correlation between chemical structure and degradation rate of the pollutants, J. Catal., 266 (2009) 199-206.

[18] A. Mills, An overview of the methylene blue ISO test for assessing the activities of photocatalytic films, Appld. Catal. B: Environmental, 128 (2012) 144-149.

[19] S. Bae, S. Kim, S. Lee and W. Choi, Dye decolorization test for the activity assessment of visible light photocatalysts: Realities and limitations, Catal. Today, 224, (2014) 21-28.

[20] A. Mills, N. Wells, Reductive photocatalysis and smart inks, Chem. Soc. Rev. 44 (2015) 2849-2864. 
[21] A. Mills, J. Wang, S.K. Lee, M. Simonsen, An intelligence ink for photocatalytic films, Chem. Commun. 21 (2005) 2721-2723.

[22] A. Mills, J. Wang, M. McGrady, Method of rapid assessment of photocatalytic activities of self-cleaning films, J. Phys. Chem. B 110 (2006) 18324-18331.

[23] A. Mills, N. Wells, C. O'Rourke, Correlation between $\Delta A b s, \Delta R G B$ (red) and stearic acid destruction rates using commercial self-cleaning glass as the photocatalyst, Catal. Today 230 (2014) 245-249.

[24] F. Dong, L. Wu, Y. Sun, M. Fu, Z. Wu, S.C. Lee, Efficient synthesis of polymeric g- $\mathrm{C}_{3} \mathrm{~N}_{4}$ layered materials as novel efficient visible light driven photocatalysts, J. Mater. Chem. 21 (2011) 15171-15174.

[25] J. Liu, T. Zhang, Z. Wang, G. Dawson, W. Chen, Simple pyrolysis of urea into graphitic carbon nitride with recyclable adsorption and photocatalytic activity, J. Mater. Chem. 21 (2011) 14398-14401.

[26] J. Li, N. Wu, Semiconductor-based photocatalysts and photoelectrochemical cells for solar fuel generation: a review, Catal. Sci. Technol. 5 (2015) 1360-1384.

[27] T.F. Tadros, Dispersion of Powders in Liquids and Stabilization of Suspensions, Structure of the Solid-Liquid Interface and Electrostatic Stabilization, Wiley-VCH, Germany, 2012, ch. 4.

[28] K. Suttiponparnit, J. Jiang, M. Sahu, S. Suvachittanont, T. Charinpanitkul, P. Biswas, Role of Surface Area, Primary Particle Size, and Crystal Phase on Titanium Dioxide Nanoparticle Dispersion Properties, Nanoscale Res. Lett. 6 (2011) 27-34.

[29] X-S. Zhang, J-Y. Hu, H. Jiang, Facile modification of a graphitic carbon nitride catalyst to improve its photoreactivity under visible light irradiation, Chem. Eng. J. 256 (2014) 230-237.

[30] M. Anik, T. Cansizoglu, Dissolution kinetics of $\mathrm{WO}_{3}$ in acidic solutions, J. Appl. Electrochem. 36 (2006) 603-608.

[31] J. Coronado, F. Fresno, M.D. Hernández-Alonso, R. Portela, Design of Advanced Photocatalytic Materials for Energy and Environmental Applications, J. Coronado, Photons, 
Electrons and Holes: Fundamentals of Photocatalysis with Semiconductors, Springer, London, 2013, pp. 25.

[32] A. Mills, N. Wells, J. Mackenzie and G. MacDonald, Kinetics of reduction of a resazurinbased photocatalytic activity ink, Catal. Today 281 (2017) 14-20.

[33] ImageJ, http://imagej.net/Fiji (Accessed: December 2016).

[34] A. Mills, C. O'Rourke, N. Wells, A smart ink for the assessment of low activity photocatalytic surfaces, Analyst, 139 (2014) 5409-5414.

[35] P. G. Tratnyek,. T. E. Reilkoff,. A. W. Lemon, M. M. Scherer, B. A.Balko, L. M. Feik, and B. D. Henegar, Visualizing Redox Chemistry: Probing Environmental Oxidation Reduction Reactions with Indicator Dyes, Chem. Educator 6 (2001) 172-179.

[36] A. Mills, N. Wells and C. O'Rourke, Correlation between the photocatalysed oxidation of methylene blue in solution and the reduction of resazurin in a photocatalyst activity indicator ink (Rz Paii), J Photochem. Photobiol. A: Chem. 330 (2016) 86-89.

[37] A. Mills and N. Wells, Smart, reusable labels for assessing self-cleaning films, Chem. Commun. 51 (2015) 4161-4163. 